OCT 301550

OSTI

\title{
Structure/Function Studies of Resorcinol-Formaldehyde (R-F) and Phenol-Formaldehyde (P-F) Copolymer lon-Exchange Resins
}
T.L. Hubler
R.T. Hallen
J.A. Franz
G.N. Brown
W.J. Shaw
J.C. Linehan
M.O. Hogan

September 1996

Prepared for

the U.S. Department of Energy,

under Contract DE-AC06-76RLO 1830

Pacific Northwest National Laboratory Operated for the U.S. Department of Eriergy by Battelie 

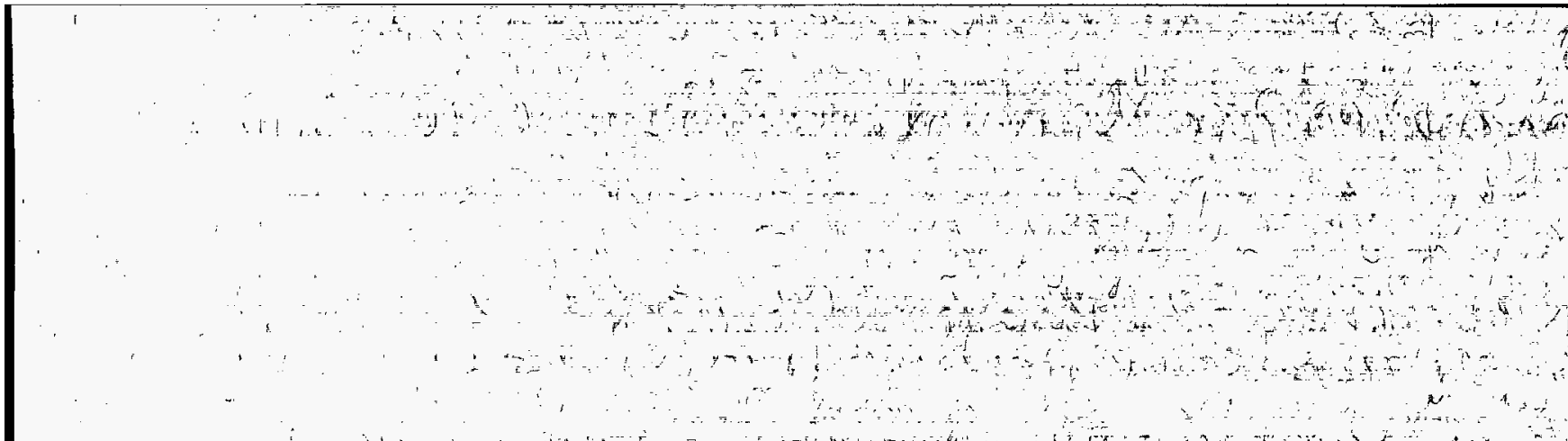

\section{DISCLAIMER}

This report was prepared as an account of work sponsored by an agency of the United States Government. Neither the United States Government nor any agency thereof, nor Battelle Memorial Institute, nor any of their employees, makes any warranty, express or implied, or assumes any legal liability or responsibility for the accuracy, completeness, or usefulness of any information, apparatus, product, or process disclosed, or represents that its use would not infringe privately owned rights. Reference herein to any specific commercial product, process, or service by trade name, trademark, manufacturer, or otherwise does not necessarily constitute or imply its endorsement, recommendation, or favoring by the United States Government or any agency thereof, or Battelle Memorial Institute. The views and opinions of authors expressed herein do not necessarily state or reflect those of the United States Government or any agency thereof.

\section{PACIFIC NORTHWESTT NÁTIOONALL LABORATÓRY operated by \\ BATTELLE MEMORIAL INSTITUTE for the UNITED STATES DEPARTMENT OF ENERGY under Contract DE-AC06-76RLO 1830}

\section{Printed in the United States of America}

Ayailable to DOE and DOE contractors from the

Office of Scientific and Technical Information, P.O. Box 62, Oak Ridge, IN 37831; prices available from (615) 576-8401.

Available to the public from the National Technical Information Service, U.S. Department of Commerce, 5285 Port Royal Rd., Springfield, VA 22161
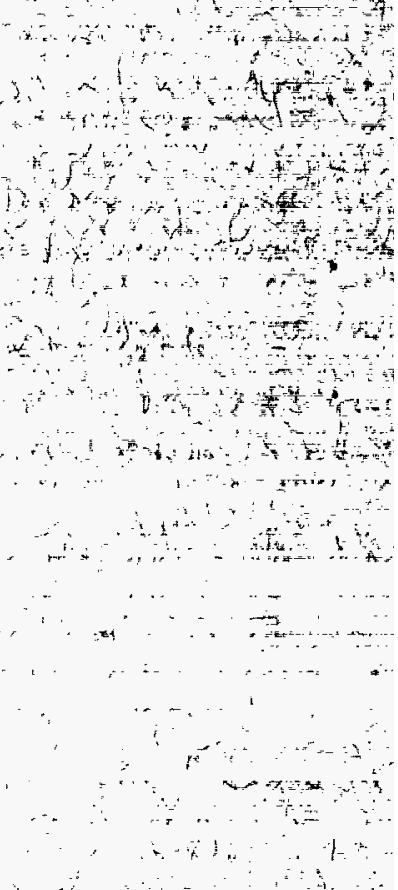


\section{Structure/Function Studies of Resorcinol-Formaldehyde (R-F) and Phenol-Formaldehyde (P-F) Copolymer Ion-Exchange Resins}

$\begin{array}{ll}\text { T.L. Hubler } & \text { R.T. Hallen } \\ \text { J.A. Franz } & \text { G.N. Brown } \\ \text { W.J. Shaw } & \text { J.C. Linehan } \\ \text { M.O. Hogan } & \end{array}$

September 1996

Prepared for

the U.S. Department of Energy,

under Contract DE-AC06-76RLO 1830

Pacific Northwest National Laboratory

Richland, Washington 99352 


\section{DISCLAIMER}

This report was prepared as an account of work sponsored by an agency of the United States Government. Neither the United States Government nor any agency thereof, nor any of their employees, makes any warranty, express or implied, or assumes any legal liability or responsibility for the accuracy, completeness, or usefulness of any information, apparatus, product, or process disclosed, or represents that its use would not infringe privately owned rights. Reference herein to any specific commercial product, process, or service by trade name, trademark, manufacturer, or otherwise does not necessarily constitute or imply its endorsement, recommendation, or favoring by the United States Government or any agency thereof. The views and opinions of authors expressed herein do not necessarily state or reflect those of the United States Government or any agency thereof. 


\section{DISCLAIMER}

Portions of this document may be illegible in electronic image products. Images are produced from the best available original document. 


\section{Summary}

This report summarizes the results of the work conducted by the Pacific Northwest National Laboratory from FY 1995-1996 on structure/function studies of resorcinol-formaldehyde (R-F) resin, an organic ionexchange resin with high selectivity for cesium ion. R-F resin is a candidate ion-exchange material for use in remediation of alkaline tank waste supernates at both the Hanford and Savannah River sites.

In FY 1994, several factors affecting the structure and hence the performance of both R-F and phenolformaldehyde (P-F) resin were elucidated. Some of the more important factors are 1) the primary structural unit of the R-F resin was determined to be a 1,2,3,4-tetrasubstituted resorcinol ring unit while P-F resins (e.g., Duolite CS- $100^{\mathrm{TM}}$ ) were found to be composed mainly of a 1,2,4-trisubstituted ring, 2) curing temperatures for the R-F resin were found to be optimal in the range of $105-130^{\circ} \mathrm{C}$, and 3) the optimal particle size for R-F resin is in the range of 20-50 mesh-sized particles.

Structure/function studies for R-F and P-F resins conducted in FY 1995 were helpful in elucidating the performance differences between the two phenolic-type resins because the differences were other than that expected on the basis of the different capacities of the two materials alone (R-F has only twice the theoretical number of ion-exchange sites as P-F, yet the performance is roughly 40-50 times greater). The technical approach used was to prepare and characterize copolymer resins. The copolymers chosen were hydroxybenzoic acids and fluorophenols.

Results from the copolymers showed that nearly all the $\mathrm{K}_{\mathrm{d}} \mathrm{s}$ for the R-F copolymers were lower compared to R-F itself, thus suggesting that capacity and/or selectivity of the resin was altered upon addition of the copolymer. For the fluorophenol copolymers, a modest reduction of the capacity was expected since only $5-10 \%$ of the R-F resin was composed of the copolymer. For the monofluorophenols, the effect on the R-F resin is primarily due to loss of ion-exchange site capacity (i.e., loss of basicity of the ion-exchange site caused by the electron-withdrawing effect of the fluorine atom), while the difluorophenols affected both ion-exchange site basicity (capacity) and crosslinking of the resin (selectivity) resulting in the much lower $\mathrm{K}_{d} \mathrm{~s}$. In general, the same trend was observed for P-F resins. The hydroxybenzoic acid copolymers also had a deleterious effect on the performance of R-F resin, which again may be related to poorer crosslinking compared to the parent R-F resin. In the case of P-F resin, the performance actually increased slightly because the capacity of the material was increased (hydroxybenzoic acids have more ion-exchange sites per unit than does phenol).

The primary focus of work in FY 1996 centered on examination of the affect that "templating ions" may have on the resin performance. Optimal preparation of R-F resin was considered to require use of potassium ions for templating of the ion-exchange site to an optimal size for the cesium ion. The completed studies, although they make a rigorous conclusion on the role of templating in the R-F resin elusive, seem to indicate that there is at best only slight differences in performance caused by use of the different alkali or "template" ions. In all cases, the sodium ion gave the best performance results.

Finally, the results of the studies have helped to clarify the relation between structure and performance differences observed for R-F and P-F resin. R-F resin undergoes chemical degradation that destroys ionexchange sites, thus resulting in lower $\mathrm{K}_{\mathrm{d}} \mathrm{s}$. The ion-exchange sites (hydroxyl groups) undergo facile conversion to quinone and ketone structures. P-F resin, though it has much lower performance for cesium ion-exchange, is significantly more chemically stable than R-F resin under the typical conditions encountered for the tank waste supernates. The reason why P-F resins have $K_{d} s$ much lower than R-F resin is that 
over $50 \%$ of the ion-exchange sites are etherified during preparation of these materials under Bibler synthetic conditions; therefore, the best performance that can be expected is less than $25 \%$ that of R-F resin. P-F resin is more chemically stable than $\mathrm{R}-\mathrm{F}$ resin primarily because the aromatic ring components are not as electron rich; hence oxidation does occur as easily. The effect is also thought to be related to the fact that there are alkyl functionalities para to all the hydroxyl groups in P-F resin, while this is not the case for the majority of the ring moieties in R-F resin. The effect of para groups is currently the subject of a research program being conducted for the Efficient Separations and Processing Crosscutting Program (ESP, EM-53). 


\section{Acknowledgments}

The authors gratefully acknowledge the data provided for this report from the experiments and analyses conducted by the following staff members: Betty E. Tanaka, Robert J. Elovich, and Jaquetta R. Deschane for performing the $K_{d}$ analyses. This work was supported by Laboratory Directed Research \& Development (LDRD) funds under the Advanced Processing Technology Initiative (APTI) at the Pacific Northwest National Laboratory. 



\section{Acronyms}

$\begin{array}{ll}\text { APTI } & \text { Advanced Processing Technology Initiative } \\ \text { BET } & \text { Brunauer, Emmet, Teller } \\ \text { BSC } & \text { Boulder Scientific Co. } \\ \text { CP-MAS } & \text { cross polarization/magic angle spinning } \\ \text { DOE } & \text { U.S. Department of Energy } \\ \text { DSSF } & \text { double-shell slurry feed } \\ \text { FID } & \text { free induction decay } \\ \text { FTIR } & \text { Fourier Transform Infrared } \\ \text { IR } & \text { Infrared } \\ \text { K } & \text { distribution coefficient } \\ \text { LDRD } & \text { Laboratory Directed Research \& Development } \\ \text { NCAW } & \text { Neutralized Current Acid Waste } \\ \text { NMR } & \text { nuclear magnetic resonance } \\ \text { P-F } & \text { phenol-formaldehyde } \\ \text { PNNL } & \text { Pacific Northwest National Laboratory } \\ \text { TGA/IR } & \text { resorcinol-formaldehyde } \\ & \end{array}$




\section{Contents}

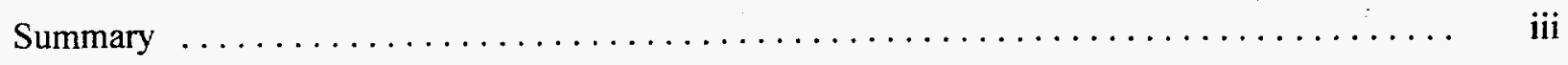

Acknowledgments $\ldots \ldots \ldots \ldots \ldots \ldots \ldots \ldots \ldots \ldots \ldots \ldots \ldots \ldots \ldots \ldots \ldots \ldots \ldots \ldots, \quad \mathrm{v}$

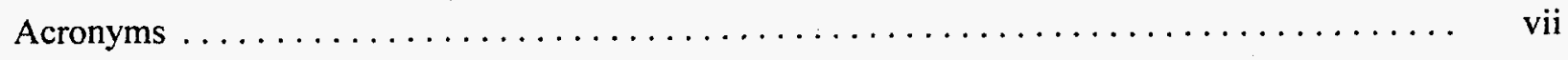

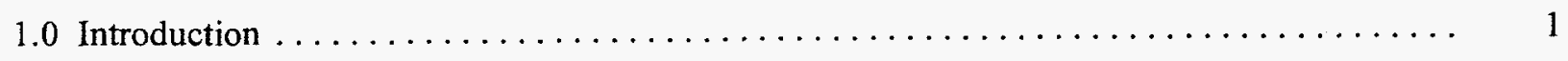

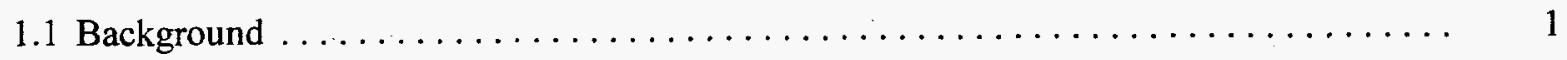

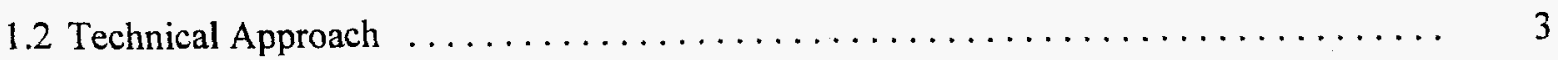

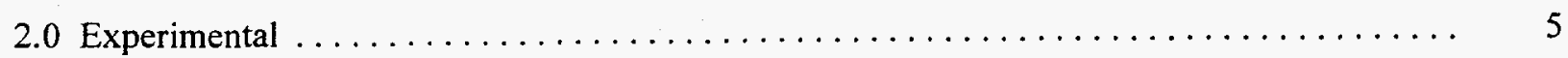

2.1 Synthesis of Resins $\ldots \ldots \ldots \ldots \ldots \ldots \ldots \ldots \ldots \ldots \ldots \ldots \ldots \ldots \ldots \ldots \ldots \ldots \ldots \ldots$

2.2 Preparations of Acid Form of R-F Resins $\ldots \ldots \ldots \ldots \ldots \ldots \ldots \ldots \ldots \ldots \ldots$

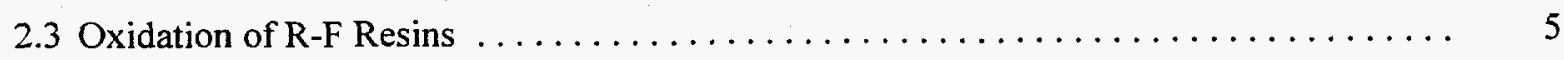

2.4 Distribution Coefficients, $\mathrm{K}_{\mathrm{d}} \mathrm{s} \ldots \ldots \ldots \ldots \ldots \ldots \ldots \ldots \ldots \ldots \ldots \ldots \ldots \ldots \ldots \ldots \ldots \ldots \ldots \ldots$

2.5 Nuclear Magnetic Resonance Spectroscopy $\ldots \ldots \ldots \ldots \ldots \ldots \ldots \ldots \ldots \ldots \ldots$

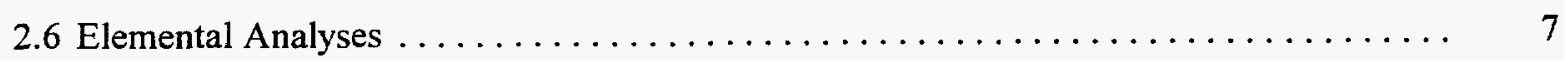

3.0 Results and Discussion $\ldots \ldots \ldots \ldots \ldots \ldots \ldots \ldots \ldots \ldots \ldots \ldots \ldots \ldots \ldots \ldots \ldots$

$3.1 \mathrm{R}-\mathrm{F}$ and P-F Copolymer Resin $\ldots \ldots \ldots \ldots \ldots \ldots \ldots \ldots \ldots \ldots \ldots \ldots \ldots \ldots \ldots \ldots \ldots \ldots$

3.2 Distribution Coefficients of R-F and P-F Copolymer Resins $\ldots \ldots \ldots \ldots \ldots \ldots$

3.3 NMR Structural Characterization of R-F and P-F Copolymers $\ldots \ldots \ldots \ldots \ldots \ldots \ldots$

3.4 Solid-state ${ }^{19}$ F NMR Characterization of Fluorophenol Copolymer Resins $\ldots \ldots \ldots \ldots \quad 17$

3.5 Elemental Analyses of the Resin Copolymers $\ldots \ldots \ldots \ldots \ldots \ldots \ldots \ldots \ldots \ldots \ldots$

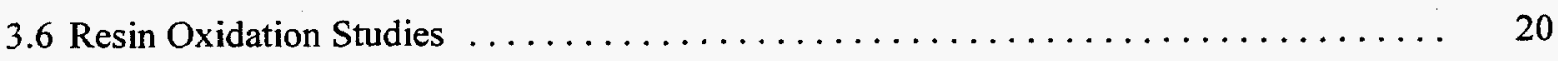

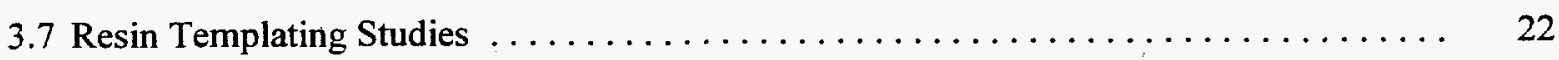

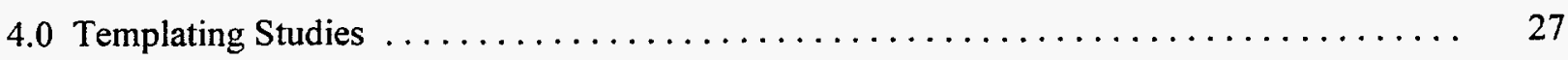

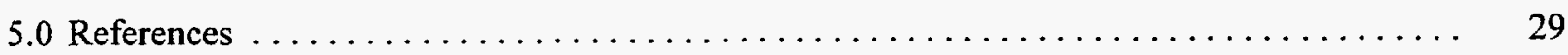




\section{Figures}

1 Resorcinol and ring numbering scheme $\ldots \ldots \ldots \ldots \ldots \ldots \ldots \ldots \ldots \ldots \ldots \ldots \ldots \ldots \ldots \ldots \ldots$

$2{ }^{13} \mathrm{C}$ NMR CP-MAS spectrum for resorcinol/phenol (90\%/10\%)

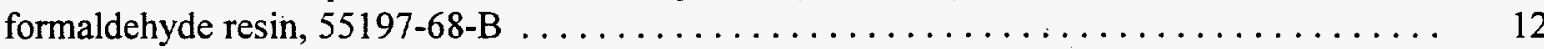

$3{ }^{13} \mathrm{C}$ NMR CP-MAS spectrum for resorcinol/3-hydroxybenzoic $(95 \% / 5 \%)$

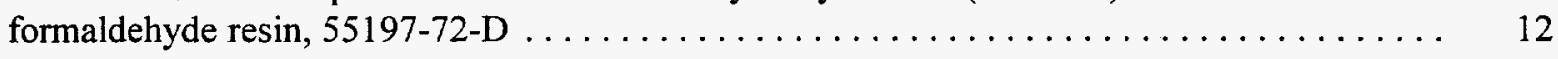

$4{ }^{13} \mathrm{C}$ NMR CP-MAS spectrum for resorcinol/3-fluorophenol $(90 \% / 10 \%)$

formaldehyde resin, 55197-96-B: a) ${ }^{1} \mathrm{H}$ and ${ }^{19} \mathrm{~F}$ decoupled spectrum, and

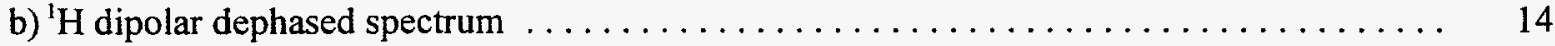

$5 \quad{ }^{13} \mathrm{C}$ NMR CP-MAS spectrum for resorcinol/3,5-difluorophenol $(90 \% / 10 \%)$

formaldehyde resin, 55197-105-B: a) ${ }^{1} \mathrm{H}$ and ${ }^{19} \mathrm{~F}$ decoupled spectrum, and

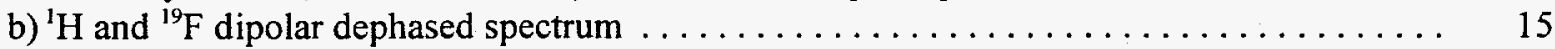

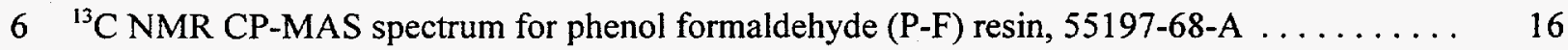

$7 \quad{ }^{13} \mathrm{C}$ NMR CP-MAS spectrum for 3-fluorophenol formaldehyde resin, 55197-99-B $\ldots \ldots \ldots \quad 16$

8 Solid-state ${ }^{19} \mathrm{~F}$ NMR spectrum for resorcinol/2-fluorophenol $(95 \% / 5 \%)$

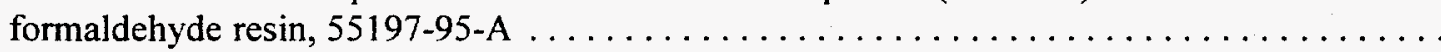

9 Solid-state ${ }^{19} \mathrm{~F}$ NMR spectrum for resorcinol/4-fluorophenol $(90 \% / 10 \%)$

formaldehyde resin, 55197-100-B

10 Solid-state ${ }^{19} \mathrm{~F}$ NMR spectrum for resorcinol/3;4-difluorophenol $(90 \% / 10 \%)$

formaldehyde resin, $55197-103-\mathrm{C}$ with sample spinning speeds a) $2.0 \mathrm{kHz}$,

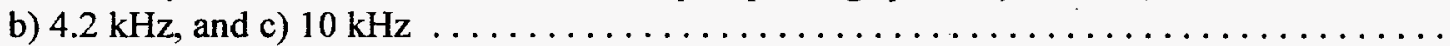

11 Oxygen uptake by selected resorcinol and phenol fluorophenol formaldehyde

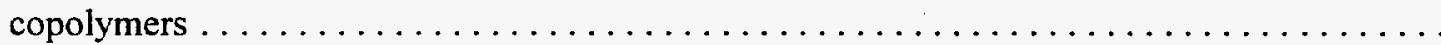

$12{ }^{13} \mathrm{C}$ CP-MAS NMR of oxidized resorcinol/3-fluorophenol $(90 \% / 10 \%)$ copolymer resin $\ldots \ldots \quad 23$

13 The relationship between swelling/contracting and selectivity for phenolic condensation polymers . . . . . . . . . . . . . . . . . . . . . . . . . . . .

14 The two primary structural elements in P-F resin $\ldots \ldots \ldots \ldots \ldots \ldots \ldots \ldots \ldots \ldots \ldots \ldots$

15 Facile oxidation of R-F resin to give para-quinones $\ldots \ldots \ldots \ldots \ldots \ldots \ldots \ldots \ldots \ldots$ 


\section{Tables}

1 Batch Distribution Coefficients for R-F and P-F Copolymer Ion-Exchange Resins $\ldots \ldots \ldots \quad 10$

2 Elemental Analyses for R-F and P-F Copolymer Ion-Exchange Resins $\ldots \ldots \ldots \ldots \ldots 21$

3 Distribution Coefficients for Ion-Templating Studies of R-F Resin in the

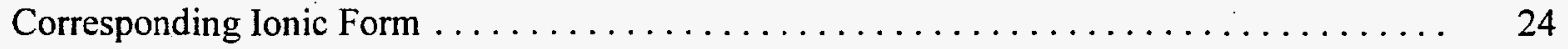

4 Distribution Coefficients for Ion-Templating Studies of R-F Resin in the Acid Form . . . . 24

5 Elemental Analyses for Alkali Metal-Templated R-F Resins $\ldots \ldots \ldots \ldots \ldots \ldots \ldots \ldots \ldots$ 


\subsection{Introduction}

\subsection{Background}

The U.S. Department of Energy's (DOE) Hanford Site, located in southeastern Washington State, occupies an area of 560 square miles and was established in 1944 to produce plutonium for the U.S. defense mission. Over the course of decades, hazardous, toxic, and radioactive chemical wastes were generated and disposed of in a variety of ways including storage in underground tanks. An estimated 180 million tons of high-level radioactive wastes are stored in 177 underground storage tanks. During production of fissile plutonium, large quantities of ${ }^{90} \mathrm{Sr}$ and ${ }^{137} \mathrm{Cs}$ were produced. The high abundance and intermediate length half-lives of these fission products are the reason that effort is directed toward selective removal of these radionuclides from the bulk waste stream before final tank waste disposal is effected. Economically, it is desirable to remove the highly radioactive fraction of the tank waste for vitrification, with the bulk of the waste disposed in a relatively low-cost method. Ion-exchange technology is being evaluated for removing cesium from Hanford Site waste tanks.

This report summarizes data and analyses performed by Pacific Northwest National Laboratory (PNNL) ${ }^{(a)}$ for both resorcinol-formaldehyde (R-F) and phenol-formaldehyde (P-F) resins and relates their observed differences in performance and chemical stability to their structure. The experimental approach used to characterize the resins was conducted using primarily two types of data: batch distribution coefficients $\left(\mathrm{K}_{\mathrm{d}} \mathrm{s}\right)$ and solid-state ${ }^{13} \mathrm{C}$ NMR. Comparison of these data for a particular resin allowed correlation of resin performance to resin structure. Additional characterization techniques included solid-state ${ }^{19} \mathrm{~F} \mathrm{NMR}$, and elemental analyses.

Initial evaluations (measured by determination of distribution coefficients, $K_{d} s$ ) for different batches of $R-F$ resin showed some variability in the performance of the resin; thus, there was a need to understand the structure of R-F resin and the important synthetic parameters that may affect the eventual performance of the product. Additionally, Duolite ${ }^{\mathrm{TM}} \mathrm{CS}-100$ (Rohm and Haas), a phenol-formaldehyde (P-F) resin, showed greater chemical stability but significantly less cesium selectivity and/or capacity than R-F resin. There was a need to understand the chemical nature of the performance differences for the two similar materials.

Structure/function studies for R-F resin were initiated at PNNL under the Advanced Processing Technology Initiative (APTI) in FY 94. These studies undertook preparation and characterization of R-F resin synthesized under a variety of conditions in order to establish the primary structure of the resin and to identify some of the important synthetic parameters critical for obtaining a quality ion-exchange product [1].

The primary structural unit of R-F resin was found to be a 1,2,3,4-tetrasubstituted resorcinol ring (Figure 1). Both nuclear magnetic resonance (NMR) and infrared (IR) spectroscopic techniques provided direct evidence for this structure. Solid-state ${ }^{13} \mathrm{C}$ cross polarization/magic angle spinning (CP-MAS) NMR spectra for ${ }^{13} \mathrm{C}$ label-enhanced resin showed the presence of two non-equivalent methylene group carbons as expected for a 1,2,3,4-tetrasubstituted resorcinol ring. Fourier Transform Infrared (FTIR) structural

(a) The Pacific Northwest National Laboratory is operated by Battelle for the U.S. Department of Energy by Battelle under Contract DE-AC06-76RLO 1830. 
analysis for R-F resin showed a primary band at $802 \mathrm{~cm}^{-1}$ corresponding to aromatic out-of-plane C-H bending, which is indicative of the 1,2,3,4-tetrasubstituted ring pattern for the resorcinol unit. FTIR analysis also indicated the likely presence of some 1,2,4,5-tetrasubstituted and/or 1,2,4-trisubstituted resorcinol ring units, which comprise $15 \%$ or less of the polymer structure, by the presence of an IR band at $865 \mathrm{~cm}^{-1}$. Additionally, elemental analyses obtained for $\mathrm{R}-\mathrm{F}$ resin in both the $\mathrm{H}^{+}$and $\mathrm{K}^{+}$forms were consistent with a 1,2,3,4-tetrasubstituted ring structure.

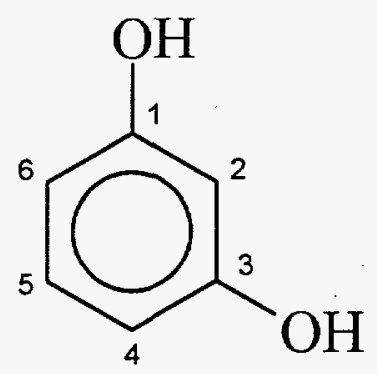

Figure 1. Resorcinol and ring numbering scheme

Some of the important synthetic parameters for R-F resin were investigated, including curing temperature and particle size. The curing temperature for $\mathrm{R}-\mathrm{F}$ resin was found to be optimal between $105^{\circ} \mathrm{C}$ and $130^{\circ} \mathrm{C}$. Curing of resin below this temperature range results in insufficient crosslinking of the polymer resin. The ion-exchange performance of the resin is reduced because the lower crosslinked resin has much lower selectivity for cesium ion. An upper limit of $130^{\circ} \mathrm{C}$ for curing temperature is suggested because significant organic decomposition of the resin was observed at $135^{\circ} \mathrm{C}$ during thermogravimetric analysis/ infrared (TGA/IR) analysis. Also, analysis of $\mathrm{K}_{d} \mathrm{~s}$ for $\mathrm{R}-\mathrm{F}$ resin cured at temperatures above $135^{\circ} \mathrm{C}$ in an inert helium atmosphere showed reduction of cesium $\mathrm{K}_{d} \mathrm{~s}$. The lower $\mathrm{K}_{d} \mathrm{~s}$ resulted from decomposition of the resin.

The optimal particle size for the R-F resin to be used in an ion-exchange process was found to be in the range of 20-50 mesh sized particles. Particles larger than 20 mesh gave lower $K_{d} s$ because ion-exchange is diffusion limited in the larger particles. For particles smaller than 50 mesh, the greater surface area of the resin presented to the solution was more easily oxidized, or otherwise chemically degraded, with a concomitant loss of ion-exchange sites.

The effects of oxidation on R-F resins were elucidated by correlation of ${ }^{13} \mathrm{C} N M R$ spectra of the resins with their respective batch $\mathrm{K}_{d} \mathrm{~s}$. These studies showed that as oxidation of the resin takes place, quinone, ketone, and ether groups become prominent functionalities in the resin, along with a simultaneous drop in the number of phenolic hydroxyl ion-exchange groups.

The method used to determine the basic structure of the R-F polymer resin was to examine the solid-state ${ }^{13} \mathrm{C}$ NMR spectra for R-F resin and to prepare selectively labeled ${ }^{13} \mathrm{C}$ enriched resin samples to correlate the fate of the chemical reagents with their functionality in the resin product. Additionally, ${ }^{133} \mathrm{Cs}$ NMR was 
used to characterize samples of R-F resin that were loaded with varying amounts of cesium ion to give insight into the nature of the ion-exchange site and the environment presented to the cesium ion. IR analysis of resin samples gave structural information about the resin by a qualitative assessment of the functional group absorptions found in the spectra.

\subsection{Technical Approach}

Modified polymers of P-F and R-F resins were prepared in order to better assess the factors affecting chemical stability. The polymer resins were modified by incorporating fluorophenols and hydroxybenzoic acids as copolymers in the resin. The derivatized R-F and P-F resins were then structurally analyzed using solid-state ${ }^{13} \mathrm{C}$ and ${ }^{19} \mathrm{~F}$ NMR and these results were correlated with their ion-exchange performance by measurement of their $\mathrm{K}_{\mathrm{d}} \mathrm{s}$. The results led to an understanding of the observed structure/performance characteristics of the P-F resins in relation to R-F resin. The effect of using different alkali metal ions to "template" the resin during synthesis such that the ion-exchange site is of optimal size for the cesium ion was also studied. The Bibler method for synthesis of R-F resin uses potassium ion as the optimal templating alkali metal ion. The approach used for the templating study was to synthesize R-F resin using the full range of alkali metal hydroxides. The resulting resins were then analyzed by solid-state NMR and distribution coefficients. Two different stoichiometries were used for the resin preparations (1 MOH: 1 resorcinol and $2 \mathrm{MOH}: 1$ resorcinol) to assess the templating effect when one or both the resorcinol ring hydroxyl groups are deprotonated during synthesis. In turn, the same analyses were performed on the corresponding acid forms of the various resins. If there was a negligible templating effect, the $\mathrm{K}_{\mathrm{d}} \mathrm{s}$ for the acid forms should theoretically be the same. 



\subsection{Experimental}

\subsection{Synthesis of Resins}

The synthesis of the R-F resin and copolymer resins was performed according to Wallace and Bibler's procedure [2], a variant of the procedure of Pennington and Williams [3]. A typical synthesis is described below: Resorcinol (33g, Aldrich, $99 \%$ ) was dissolved in $250 \mathrm{~mL}$ of deionized water in a $500 \mathrm{~mL}$ beaker. A $6 \mathrm{M} \mathrm{KOH}$ solution $(16.8 \mathrm{~g} \mathrm{KOH}$ in $50 \mathrm{~mL}$ of deionized water) was added to the resorcinol solution with stirring. The initial color of the solution was a pale red-violet, which turned yellow brown within 1-2 min. The solution temperature was brought to $90^{\circ} \mathrm{C}$, stirred for $1 \mathrm{~h}$, then cooled to room temperature. Formalin $(87.5 \mathrm{~mL}$, Aldrich, $37 \%$ solution) was added all at once to the resorcinol/KOH solution and stirred for $10 \mathrm{~min}$. The whole mixture was poured into a pyrex baking dish (7" x 12") and placed in a conventional oven at $105^{\circ} \mathrm{C}$ (the oven was situated in a fume hood) for about $20 \mathrm{~h}$. The resulting hard glassy resin was then ground using a disk mill and sieved to obtain 20-50 mesh-sized particles. In general, all characterization of the resins was performed on the potassium salt form thus obtained; however some resins were converted to their acid forms as described below.

\subsection{Preparation of Acid Form of R-F Resins}

The acid form of the resins were obtained by the following procedure. About $15 \mathrm{~g}$ of resin was placed in a jar with screw cap lid, and $75 \mathrm{~mL}$ of deionized water was added. The jar(s) of resin were placed on an orbital shaker/mixer for $20 \mathrm{~h}$, after which the resin was filtered using a Büchner filtration apparatus. The procedure of mixing and filtering was then carried out for the following solutions in the order stated: $2 M$ $\mathrm{NaOH}$ solution for $20 \mathrm{~h}, 2 \mathrm{MNaOH}$ solution for $20 \mathrm{~h}$, deionized water for $20 \mathrm{~h}, 5 \% \mathrm{HNO}_{3}$ for $24 \mathrm{~h}$, and $5 \% \mathrm{HNO}_{3}$ for $24 \mathrm{~h}$. A thorough rinse of the resin with deionized water was accomplished during the final filtration step. The resin was then dried in the oven at $105^{\circ} \mathrm{C}$ overnight.

\subsection{Oxidation of R-F Resins}

Controlled air oxidation some resins were carried out using a high vacuum line outfitted with a gas uptake measurement apparatus. The polymer resins (typically $0.25 \mathrm{~g}$ ) were dispersed in $50 \mathrm{~mL} 1 M \mathrm{NaOH}, 6 M$ $\mathrm{NaOH}$, and Neutralized Current Acid Waste (NCAW) simulant supernate. The procedure consisted of sparging the $\mathrm{NaOH}$ or NCAW solutions with nitrogen, then the weighed-out resin sample was introduced into sparged solution and the vessel containing the resin and solution were placed on the gas uptake apparatus. The resin containing solution was then degassed using three freeze-pump-thaw cycles. After degassing and equilibration of the flask to atmospheric pressure with oxygen (the solution was not stirred until after equilibration), the uptake of oxygen by the resin was measured using the calibrated line.

\subsection{Distribution Coefficients, $K_{d} s$}

The batch distribution coefficient $\left.\left(\mathrm{K}_{d}=[\mathrm{Cs}]_{\text {solid }} / \mathrm{Cs}\right]_{\text {liquid }}\right)$ is an equilibrium measure of the ability of the solid phase ion-exchange material to remove an ion from solution. For the cesium $\mathrm{K}_{d}$ tests described in this report, $0.1 \mathrm{~g}$ of the resin sample (normally the $\mathrm{K}^{+}$-form) was placed into standard $20-\mathrm{mL}$ scintillation vials and 
contacted with $15 \mathrm{~mL}$ of the $3.9 \mathrm{MNa}$ double-shell slurry feed (DSSF) waste simulant for $72 \mathrm{~h}$. The feed solution was radio labeled by addition of approximately $12 \mathrm{nCi} / \mathrm{mL}^{137} \mathrm{Cs}$. Cesium concentrations were determined by gamma counting [4]. $\mathrm{K}_{d} \mathrm{~s}(\mathrm{~mL} / \mathrm{g})$ were determined by measuring the analyte concentration in solution before and after contact and calculating the quantity of analyte on the adsorbent by difference, using the relationship:

$$
\mathrm{K}_{\mathrm{d}}=\frac{\left(\mathrm{C}_{\mathrm{i}}-\mathrm{C}_{\mathrm{f}}\right)}{\mathrm{C}_{\mathrm{f}}} * \frac{\mathrm{V}}{\mathrm{M}^{*} \mathrm{~F}}
$$

where $C_{i}$ is the initial concentration of the ion of interest in the feed solution prior to contact, $C_{f}$ is the concentration after contact, $\mathrm{V}$ is the solution volume, $\mathrm{M}$ is the exchanger mass and $\mathrm{F}$ is the mass of dry ion exchanger divided by the mass of wet ion exchanger. $K_{d}$ represents the theoretical volume of solution that can be processed per mass of exchanger under equilibrium conditions. Factor $\mathrm{F}$ was determined by drying the material at $105^{\circ} \mathrm{C}$ for $24 \mathrm{~h}$.

The composition of the DSSF waste simulant is as follows:

$\begin{array}{ll}\frac{\text { Species }}{\mathrm{Na}^{+}} & \frac{\text { DSSF. M }}{3.90 \mathrm{E}+00} \\ \mathrm{~K}^{+} & 9.23 \mathrm{E}-02 \\ \mathrm{Rb}^{+} & 8.57 \mathrm{E}-05 \\ \mathrm{Cs}^{+} & 7.00 \mathrm{E}-05 \\ \mathrm{Sr}^{2+} & 6.00 \mathrm{E}-07 \\ \mathrm{Al}^{3+} & 3.43 \mathrm{E}-01 \\ \mathrm{SO}_{4}{ }^{2-} & 1.19 \mathrm{E}-01 \\ \mathrm{HPO}_{4}{ }^{2-} & 1.98 \mathrm{E}-02 \\ \mathrm{OH}^{-} \text {(free) } & 1.32 \mathrm{E}+00 \\ \mathrm{OH}^{-} \text {(total) } & 4.08 \mathrm{E}+00 \\ \mathrm{CO}_{3}{ }^{2-} & 1.58 \mathrm{E}-01 \\ \mathrm{NO}_{2}{ }^{-} & 3.43 \mathrm{E}-01 \\ \mathrm{NO}_{3}{ }^{-} & 1.32 \mathrm{E}+00 \\ \mathrm{~F}^{-} & 7.05 \mathrm{E}-02\end{array}$

\subsection{Nuclear Magnetic Resonance Spectroscopy}

Solid-state NMR spectra were obtained using a Chemagnetics model CMX-300/100 solid-state NMR spectrometer equipped with Chemagnetics high-speed spinning CP-MAS probes. Solid-state ${ }^{13} \mathrm{C} \mathrm{CP-MAS}$ spectra were obtained using $4.5 \mu \mathrm{s} 90^{\circ}$ proton pulses, 2 ms contact times, and about $55 \mathrm{kHz}$ high power decoupling amplitudes with two-second recycle delays. Spectra were collected at $12 \mathrm{kHz}$ magic angle spinning speeds, necessitating an offset of the carbon matching amplitude by $12 \mathrm{kHz}$ from the static HartmanHahn match. Single pulse excitation (Bloch decay) spectra were obtained using a $4.5 \mu \mathrm{s} 90^{\circ}$ carbon observe pulse with $55 \mathrm{kHz}$ proton-dipolar decoupling during carbon free induction decay (FID) acquisition.

Solid-state ${ }^{19} \mathrm{~F}$ NMR spectra were collected as Bloch Decay spectra with high power proton decoupling $\left(40 \mathrm{~W}\right.$ ) and $4.0 \mu \mathrm{s} 45^{\circ}$ pulses. Separation of the ${ }^{1} \mathrm{H}$ and ${ }^{19} \mathrm{~F}$ signals was accomplished using filters that effected $165 \mathrm{~dB}$ of separation between the two channels. The standard MAS speed was $10 \mathrm{kHz}$. 


\subsection{Elemental Analyses}

Elemental analyses for carbon and hydrogen, and nitrogen were performed as combustion analyses using a Perkin-Elmer Model 240-B Elemental Analyzer, and for the various alkali metal ions ( $\mathrm{Li}, \mathrm{Na}, \mathrm{K}, \mathrm{Rb}, \mathrm{Cs}$ ) using a Varian SpectrAA 800 spectrometer with air-acetylene flame and deuterium background correction. Resin samples for alkali metal analyses were digested using concentrated nitric acid. In addition to the relevant alkali metal analysis, the acid forms of the resins were analyzed for nitrogen and sodium content as they were treated with both sodium hydroxide and nitric acid during conversion to the acid form. 



\subsection{Results and Discussion}

\subsection{R-F and P-F Copolymer Resins}

In most cases, copolymer R-F and P-F resins containing $5 \%$ and $10 \%$ mole basis of the comonomer were prepared. The comonomers used were 2-fluorophenol, 3-fluorophenol, 4-fluorophenol, 2,5-difluorophenol, 3,4-difluorophenol, 3,5-difluorophenol, 2-hydroxybenzoic acid (salicylic acid), 3-hydroxybenzoic acid, and para-toluic acid. Additionally, some R-F resins were prepared as copolymers by addition of phenol and an attempt was made to prepare $100 \%$ polymer resins of each of the comonomers listed above. The preparations were carried out using standard preparative procedures, which have been previously described $[1,2]$; the only difference in the procedures for this study was that the appropriate amount of comonomer was added to either resorcinol or phenol.

Of the comonomers listed above, only 2-fluorophenol, 3-fluorophenol, and 3,5-difluorophenol yielded polymeric materials, which were macroscopically similar to R-F or P-F resin. The other materials did not polymerize appreciably and/or underwent chemical decomposition during synthesis resulting in brown powders, which were not tested further.

\subsection{Distribution Coefficients of R-F and P-F Copolymer Resins}

Table 1 lists the $\mathrm{K}_{d} \mathrm{~s}$ for the R-F and P-F copolymer resins synthesized at PNNL. The batch distribution coefficients were run in duplicate and a sample of R-F resin (BSC-187) prepared by Boulder Scientific, Inc. was run for comparison. The following conclusions may be made concerning the results:

- All R-F resin copolymers have $\mathrm{K}_{\mathrm{d}} \mathrm{s}$ that are at least one order of magnitude greater than the P-F resins.

- In nearly all cases, copolymerization of R-F resin with the fluorophenols and hydroxybenzoic acids reduced the performance of the resins.

- In general, the $\mathrm{K}_{\mathrm{d}} \mathrm{s}$ were higher for monofluorophenol derivatives than difluorophenol derivatives, indicating that the greater the number of electron-withdrawing fluorine atoms leads to reduced basicity of the fixed ionic group on the phenolic ring.

- Notably, hydroxybenzoic acid derivatives for R-F resins had lower $\mathrm{K}_{\mathrm{d}} \mathrm{s}$ than the fluorophenol derivatives; the situation is reversed for the P-F resins. Therefore, these materials apparently enhance the performance of $\mathrm{P}-\mathrm{F}$ resin by increasing the capacity of the resin.

Several of the R-F resin copolymers had higher $\mathrm{K}_{\mathrm{d}} \mathrm{s}$ when the amount of copolymer was doubled (10\% vs. $5 \%$ ). These included the resins made with phenol, salicylic acid, 3-fluorophenol, 4-fluorophenol, and 2,5-difluorophenol. For the phenol resins, this particular reversal of $\mathrm{K}_{\mathrm{d}}$ magnitude was observed only with the 2,5-difluorophenol copolymer. The fluorophenol and phenol copolymer R-F resins would be expected to have performances reduced by at least $5 \%$ due to loss of capacity (for the $10 \%$ copolymer resins) and possibly $10 \%$ if all the copolymer ion-exchange groups are inactivated; hence, the reversal of $\mathrm{K}_{\mathrm{d}}$ magnitudes is not clearly understood. Importantly, for the 4-substituted fluorophenol copolymers, the $\mathrm{K}_{d} s$ are substantially less 
Table 1. Batch Distribution Coefficients for R-F and P-F Copolymer Ion-Exchange Resins

\begin{tabular}{|c|c|c|}
\hline Sample & $\mathrm{K}_{\mathrm{d}}(\mathrm{mL} / \mathrm{g})$ & Description \\
\hline PNL 55197-68-B & 4910,4938 & $90 \%$ Resorcinol, $10 \%$ phenol \\
\hline PNL 55197-69-A & 4886,4830 & $95 \%$ Resorcinol, $5 \%$ phenol \\
\hline PNL 55197-71-A & 3785,3732 & $90 \%$ Resorcinol, $10 \%$ salicylic acid \\
\hline PNL 55197-71-B & 2849,2992 & 95\% Resorcinol, $5 \%$ salicylic acid \\
\hline PNL 55197-72-C & 4034,4148 & $90 \%$ Resorcinol, $10 \%$ 3-hydroxybenzoic acid \\
\hline PNL 55197-72-D & 4591,4590 & $95 \%$ Resorcinol, 5\% 3-hydroxybenzoic acid \\
\hline PNL 55197-94-A & 4522,4534 & $90 \%$ Resorcinol, $10 \%$ 2-fluorophenol \\
\hline PNL 55197-95-A & 4990,4757 & 95\% Resorcinol, 5\% 2-fluorophenol \\
\hline PNL 55197-96-B & 5278,5389 & $90 \%$ Resorcinol, $10 \%$ 3-fluorophenol \\
\hline PNL 55197-99-A & 4665,4557 & 95\% Resorcinol, 5\% 3-fluorophenol \\
\hline PNL 55197-100-B & 3835,3831 & $90 \%$ Resorcinol, $10 \%$ 4-fluorophenol \\
\hline PNL 55197-100-C & 3228,3288 & 95\% Resorcinol, 5\% 4-fluorophenol \\
\hline PNL 55197-102-A & 4017,3962 & $90 \%$ Resorcinol, $10 \%$ 2,5-difluorophenol \\
\hline PNL 55197-102-B & 3999,3894 & 95\% Resorcinol, 5\% 2,5-difluorophenol \\
\hline PNL 55197-103-C & 3607,3234 & $90 \%$ Resorcinol, $10 \%$ 3,4-difluorophenol \\
\hline PNL 55197-104-A & 4310,3798 & 95\% Resorcinol, 5\% 3,4-difluorophenol \\
\hline PNL 55197-105-B & 4356,4398 & $90 \%$ Resorcinol, $10 \%$ 3,5-difluorophenol \\
\hline PNL 55197-105-C & 4401,4316 & $95 \%$ Resorcinol, 5\% 3,5-difluorophenol \\
\hline PNL 55197-68-A & 217,214 & $100 \%$ Phenol \\
\hline PNL 55197-69-C & 239,239 & $90 \%$ Phenol, $10 \%$ salicylic acid \\
\hline PNL 55197-70-A & 285,286 & $95 \%$ Phenol, $5 \%$ salicylic acid \\
\hline PNL 55197-71-D & 228,230 & $90 \%$ Phenol, $10 \%$ 3-hydroxybenzoic acid \\
\hline PNL 55197-72-A & 234,235 & 95\% Phenol, 5\% 3-hydroxybenzoic acid \\
\hline PNL 55197-95-C & 220,227 & $90 \%$ Phenol, 10\% 2-fluorophenol \\
\hline PNL 55197-96-A & 245,243 & 95\% Phenol, 5\% 2-fluorophenol \\
\hline PNL 55197-99-C & 204,205 & $90 \%$ Phenol, $10 \%$ 3-fluorophenol \\
\hline PNL 55197-100-A & 219,224 & 95\% Phenol, 5\% 3-fluorophenol \\
\hline PNL 55197-101-B & 219,222 & $90 \%$ Phenol, $10 \%$ 4-fluorophenol \\
\hline PNL 55197-101-C & 201,198 & 95\% Phenol, 5\% 4-fluorophenol \\
\hline PNL 55197-102-C & 118,118 & $90 \%$ Phenol, $10 \%$ 2,5-difluorophenol \\
\hline PNL 55197-103-A & 139,122 & 95\% Phenol, 5\% 2,5-difluorophenol \\
\hline PNL 55197-104-B & 98,98 & 90\% Phenol, $10 \%$ 3,4-difluorophenol \\
\hline PNL 55197-104-C & 139,138 & 95\% Phenol, 5\% 3,4-difluorophenol \\
\hline PNL 55197-106-A & 135,130 & $90 \%$ Phenol, $10 \%$ 3,5-difluorophenol \\
\hline PNL 55197-106-B & 147,148 & $95 \%$ Phenol, 5\% 3,5-difluorophenol \\
\hline PNL 55197-108-B & 141,143 & $90 \%$ Phenol, $10 \%$ para-toluic acid \\
\hline PNL 55197-108-C & 143,164 & $95 \%$ Phenol, $5 \%$ para-toluic acid \\
\hline PNL 55197-109-A & 182,159 & $99 \%$ Phenol, $1 \%$ para-toluic acid \\
\hline PNL 55197-95-B & 11,10 & $100 \%$ 2-Fluorophenol \\
\hline PNL 55197-99-B & 30,28 & $100 \%$ 3-Fluorophenol \\
\hline PNL 55197-108-A & 16,17 & $100 \%$ 3,5-Difluorophenol \\
\hline BSC BSC187 & 1705,1672 & $100 \%$ Resorcinol \\
\hline
\end{tabular}


than would be expected on the basis of capacity loss alone. Clearly, reduced crosslinking of the polymer resin has had a deleterious effect on performance. Generally, the para-substituted materials cannot crosslink polymer strands and are used for preparation of the class of cyclic oligomers known as calixarenes [5]. Whether reduced crosslinking and/or actual oxidation of the monomer accounts for the lower magnitude $\mathrm{K}_{d} s$ is not known at this time.

For the P-F copolymer resins, the effect of the increased capacity of the comonomer component can clearly be seen with the hydroxybenzoic acid derivatives. Interestingly, the balance between crosslinking effects and capacity is observed for the salicylic acid case where both $5 \%\left(\mathrm{~K}_{\mathrm{d}}=285 \mathrm{~mL} / \mathrm{g}\right)$ and $10 \%\left(\mathrm{~K}_{\mathrm{d}}=239 \mathrm{~mL} / \mathrm{g}\right)$ copolymerization with phenol enhances the performance of the resin. In the $5 \%$ case, there is less additional capacity because there is less salicylic acid, but there is less apparent disruption of polymer crosslinking, and the $K_{d}$ is larger.

Phenol copolymers with para-toluic acid were prepared for study and comparison to the commercially available Duolite CS-100 ${ }^{\mathrm{TM}}$ resin (Rohm and Haas), which contains carboxylic acid functionality [6]. These resins show similar performance to the Duolite CS-100 resin, and the trend of decreasing $\mathrm{K}_{\mathrm{d}}$ in going from $1 \%$ to $10 \%$ seems to indicate that performance decreases probably because crosslinking is affected by the comonomer. The para-toluic acid is unable to crosslink because of its 1,4-disubstituted ring configuration.

Synthesis of resins from the comonomer additives to the R-F and P-F resins was attempted. Resin-like materials did form for 2-fluorophenol, 3-fluorophenol, and 3,5-difluorophenol; however, these materials had very low selectivity and capacity for cesium ion. A sample of R-F resin prepared by Boulder Scientific Company had poor performance, but this was apparently due to the age (nearly 8 years old) and extensive air oxidation of the sample.

\subsection{NMR Structural Characterization of R-F and P-F Copolymers}

This section describes solid-state ${ }^{13} \mathrm{C}$ CP-MAS NMR spectral characterization of the resin copolymers. Section 3.4 describes solid-state ${ }^{19} \mathrm{~F}$ NMR spectra and their use in characterization of the amount of crosslinking that is occurring for the resins containing the fluorophenol copolymers.

The solid-state ${ }^{13} \mathrm{C}$ NMR CP-MAS spectrum for resorcinol/phenol $(90 \% / 10 \%)$ formaldehyde resin is shown in Figure 2. The spectra looks essentially like a combination of R-F and P-F spectra in the appropriate ratios with phenolic hydroxyl carbons at $155 \mathrm{ppm}$ (with shoulder for the phenol copolymer), $120 \mathrm{ppm}$ (with shoulder), and $22 \mathrm{ppm}$. A small amount of ether functionality at $60 \mathrm{ppm}$ can be seen and is consistent with ether formation seen in P-F resin [1]. There is also a sharp resonance at $172 \mathrm{ppm}$, which indicates the presence of residual formaldehyde in the resin matrix, as has been previously observed.

The spectra for the hydroxybenzoic acid copolymer resins is similar, however, small amounts ether/benzylic alcohol functionality are observed at $40-70 \mathrm{ppm}$. The ether/benzylic alcohol functionality is much more pronounced in the 3-hydroxybenzoic acid, and yet the $\mathrm{K}_{\mathrm{d}}$ for the 3-hydroxybenzylic acid copolymer is significantly larger, suggesting that a crosslinking effect, and not merely oxidation of the resin may account for the observed performance differences. The spectrum for resorcinol/3-hydroxybenzoic acid $(95 \% / 5 \%)$ formaldehyde resin is shown in Figure 3. 


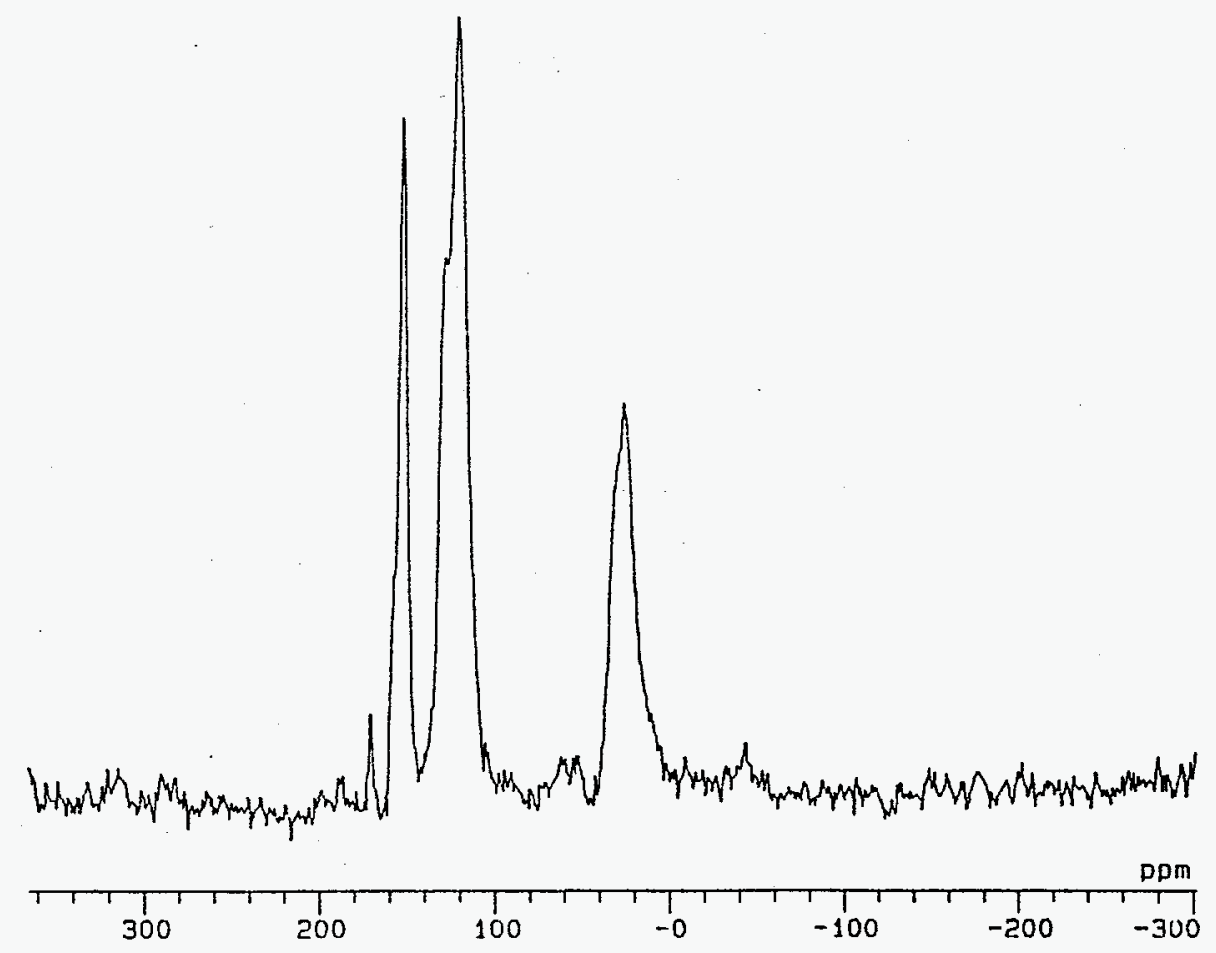

Figure 2. ${ }^{13} \mathrm{C}$ NMR CP-MAS spectrum for resorcinol/phenol $(90 \% / 10 \%)$ formaldehyde resin, 55197-68-B

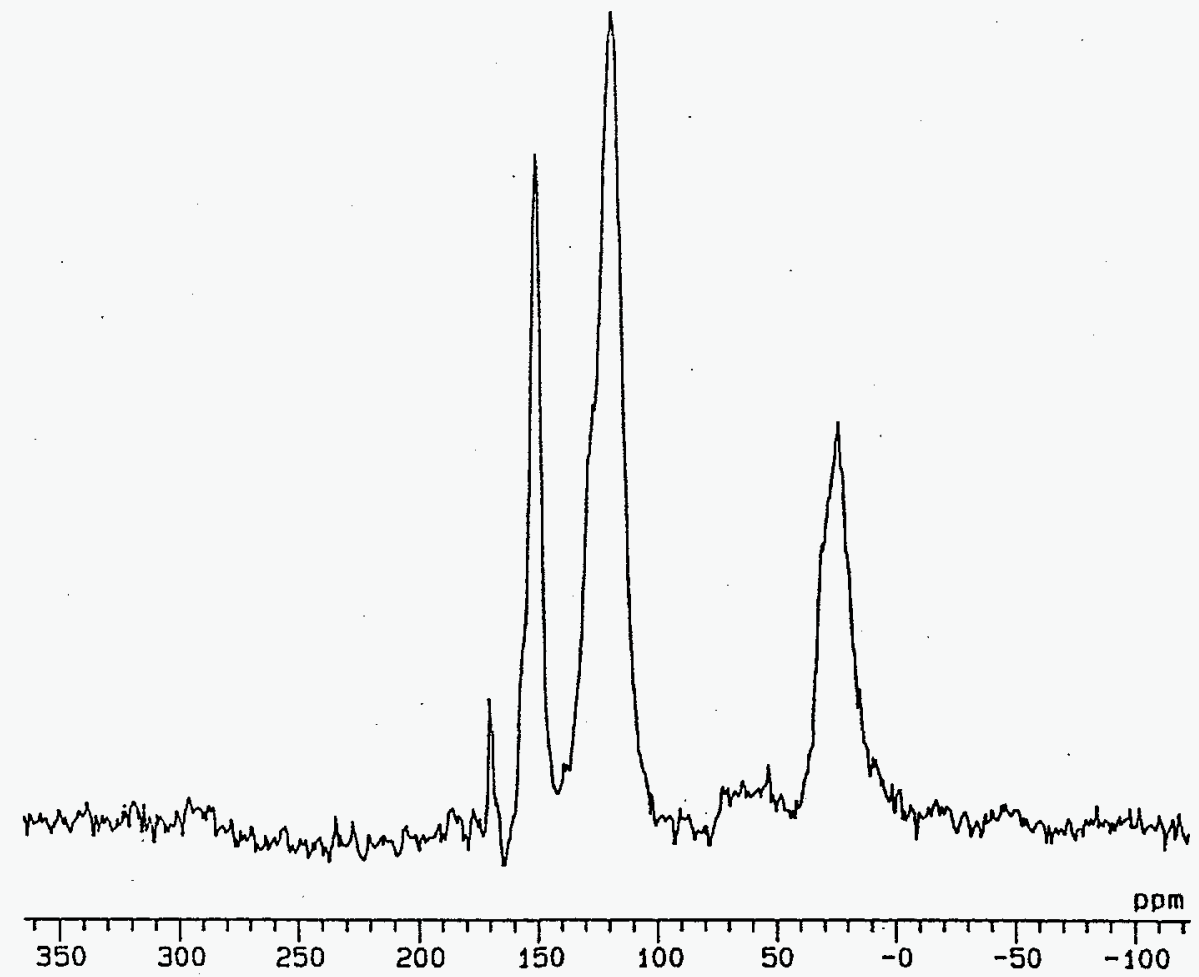

Figure 3. ${ }^{13} \mathrm{C}$ NMR CP-MAS spectrum for resorcinol/3-hydroxybenzoic acid $(95 \% / 5 \%)$ formaldehyde resin, 55197-72-D 
In Figure 4, two ${ }^{13} \mathrm{C}$ NMR CP-MAS spectra are shown that illustrate spectral editing methods that may be used to obtain structural information about the copolymer resins. In Figure $4 \mathrm{a}$, the standard ${ }^{1} \mathrm{H}$ and ${ }^{19} \mathrm{~F}$ decoupled spectrum of resorcinol/3-fluorophenol $(90 \% / 10 \%)$ is shown. The resonances are broadened slightly suggesting a higher content of free radicals than is present in R-F itself. Again, the three primary frequency domains observed are at $22 \mathrm{ppm}$ for the methylene groups, the balance of the aromatic ring carbons at approximately $120 \mathrm{ppm}$, and phenolic carbons at $150 \mathrm{ppm}$. There also appears to be some quinone/ketone functionality in the 180-200 ppm range, as well as some alcohol functionality indicated by the broad resonance around $40-70 \mathrm{ppm}$. In Figure $4 \mathrm{~b}$, the same spectrum is observed, but with ${ }^{\mathrm{l}} \mathrm{H}$ dipolar dephasing, which essentially removes all protonated carbons from the spectrum as observed in Figure 4a. Thus, the methylene and alcohol resonances from $20-70 \mathrm{ppm}$ "disappear" from the spectrum, along with some of the protonated aromatic ring carbons. Similarly, a ${ }^{19} \mathrm{~F}$ dipolar dephased spectrum was obtained, but gives little additional information as the fluorine carbon resonance occurs at about $160 \mathrm{ppm}$ as a shoulder on the phenolic resonance. The solid-state ${ }^{19} \mathrm{~F}$ NMR spectrum of this resin is discussed in Section 3.4 and offers data concerning the crosslinking of the comonomer for this resin. It should be noted that despite the appearance of some oxidation in this resin, there was little effect on performance; indeed the $\mathrm{K}_{d}$ for this resin was at or above that for standard R-F resin.

For the difluorophenol resin derivatives, there appeared to be ketone/quinone and benzylic alcohol functionality present in variable amounts in the resins prepared as copolymers with resorcinol. Figure 5 shows a representative ${ }^{13} \mathrm{C}$ CP-MAS spectrum, which is ${ }^{1} \mathrm{H}$ and ${ }^{19} \mathrm{~F}$ decoupled in Figure $5 \mathrm{a}$ and both ${ }^{1} \mathrm{H}$ and ${ }^{19} \mathrm{~F}$ dipolar-dephased in Figure $5 \mathrm{~b}$. In this case, the resin clearly contains a large amount of benzylic alcohol, which is a result of incomplete condensation reaction occurring between aromatic rings. This suggests that crosslinking of the resin is incomplete, and that curing at a higher temperature may provide a solution to optimize the performance of these resins.

For the phenol series of polymers, great similarity is observed in comparison to the resorcinol derivatives. $\dot{\mathrm{P}}-\mathrm{F}$ resin itself clearly shows that there is a significant fraction of ether groups with the broad resonance around $60-75 \mathrm{ppm}$ (Figure 6). The hydroxybenzoic acid copolymers with phenol all show a large ether resonance as expected, based on the parent P-F resin spectrum itself; it would be difficult to distinguish any significant oxidation arising from the hydroxybenzoic acid component of the polymer. A prominent resonance at $170-172 \mathrm{ppm}$ is also observed and can be assigned as the carboxylate carbon of the hydroxybenzoic acid; it is possible that a small resonance due to entrapped formaldehyde may be overlapped by this resonance. For the fluorophenol resins, significant amounts of ketone/quinone and ether/benzylic alcohol functionalities were observed in the spectra. The spectrum for 3-fluorophenol formaldehyde resin is shown in Figure 7 and is unremarkable with the exception of the prominent ether/benzylic alcohol resonance at $50-70 \mathrm{ppm}$. The presence of this resonance indicates that the resin has undergone significant reduction in the number of ion-exchange sites through etherification of the ring hydroxyls (capacity reduction) and/or reduction of crosslinking (compared to P-F resin), in turn affecting selectivity of the resin for cesium ion. The spectra were similar for the 2-fluorophenol formaldehyde resin and 3,5-difluorophenol formaldehyde resin. 


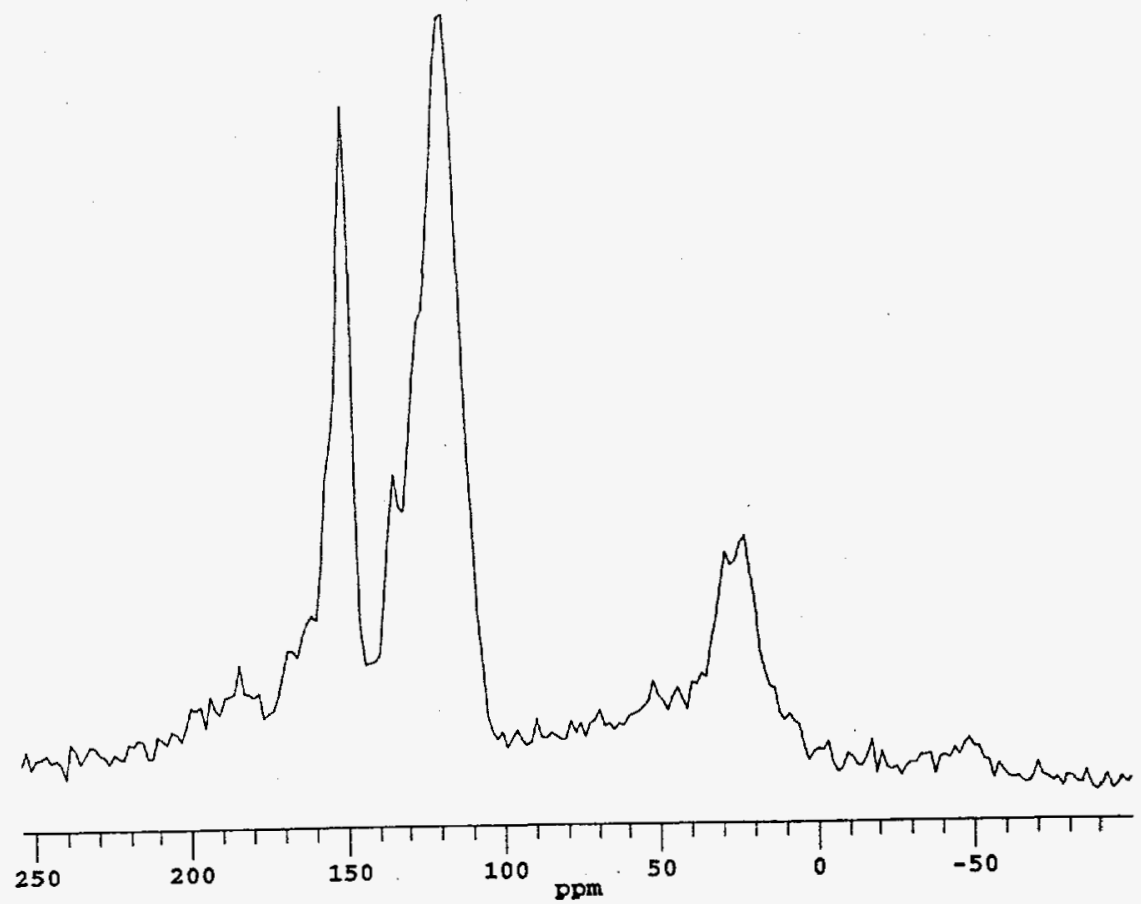

(a)

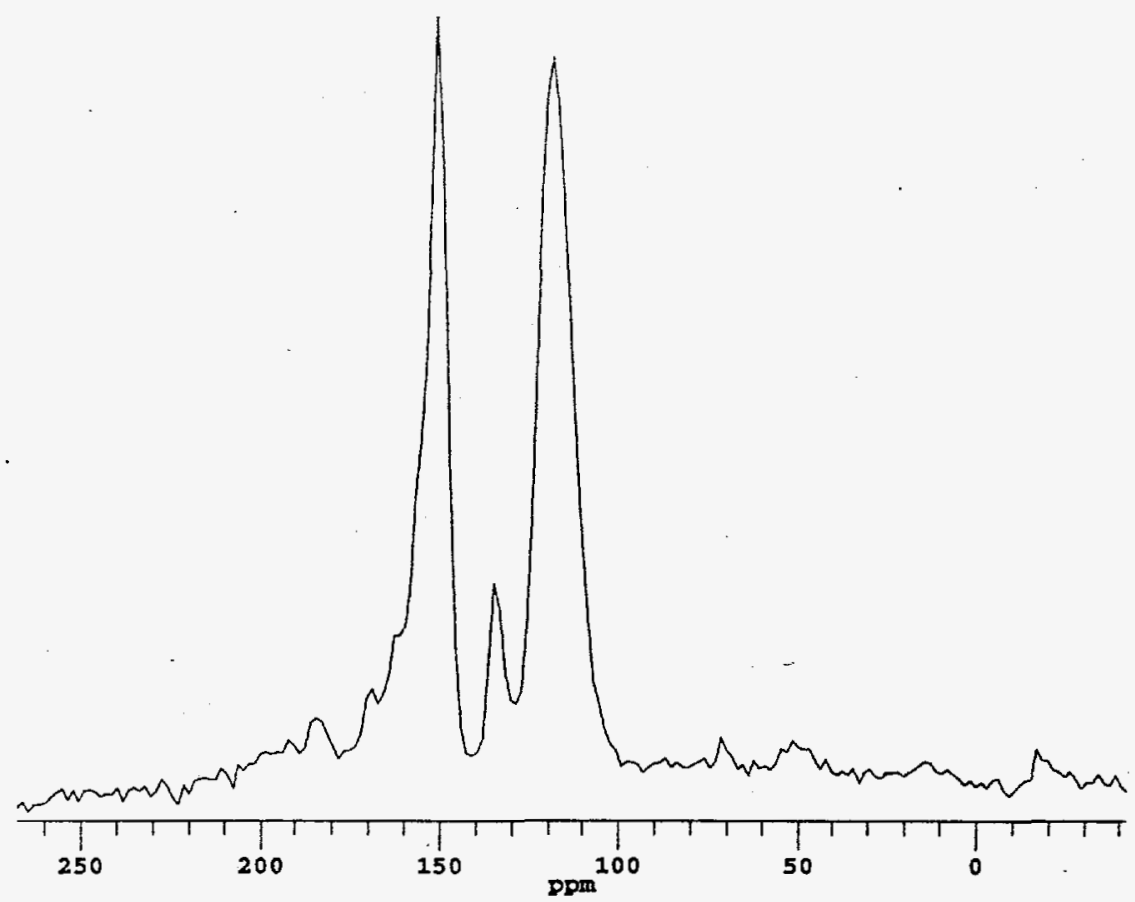

(b)

Figure 4. ${ }^{13} \mathrm{C}$ NMR CP-MAS spectrum for resorcinol/3-fluorophenol $(90 \% / 10 \%)$ formaldehyde resin, 55197-96-B: a) ${ }^{1} \mathrm{H}$ and ${ }^{19} \mathrm{~F}$ decoupled spectrum, and b) ${ }^{1} \mathrm{H}$ dipolar dephased spectrum 


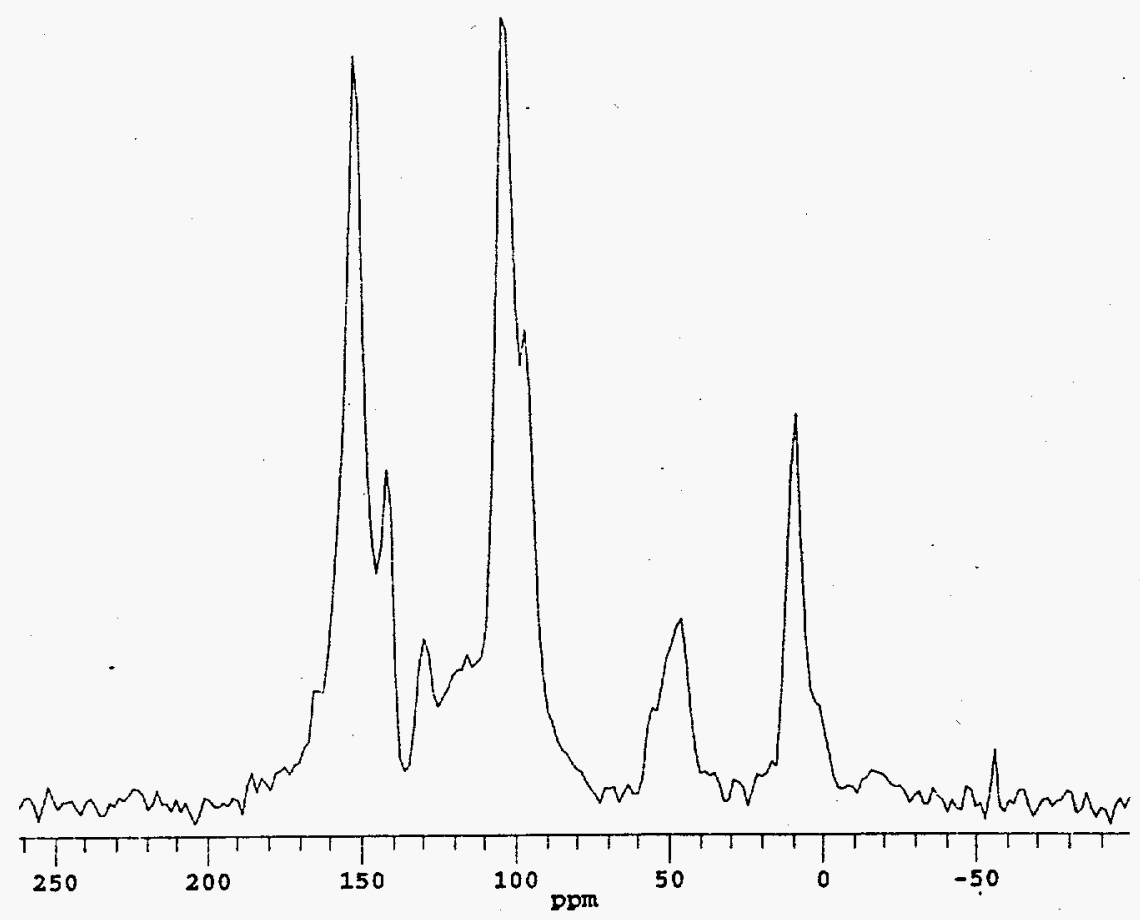

(a)

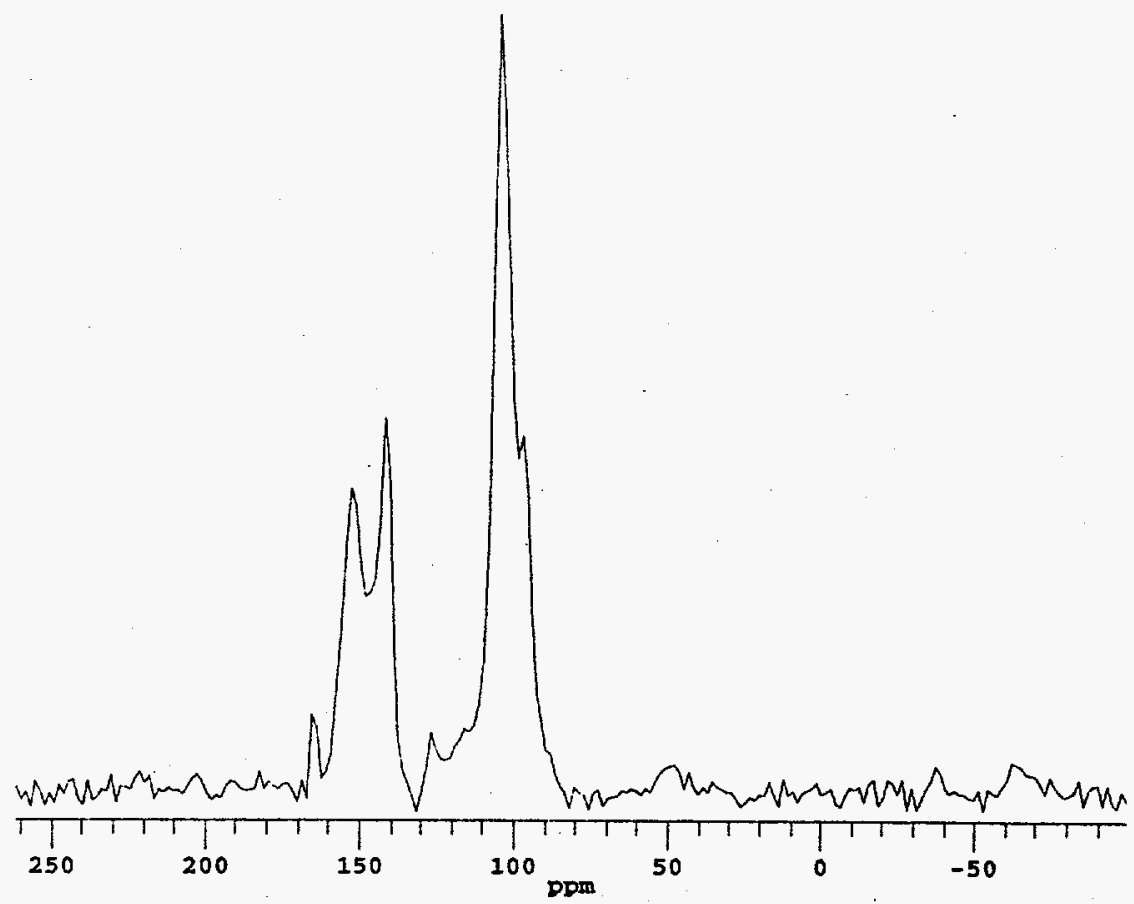

(b)

Figure 5. ${ }^{13} \mathrm{C}$ NMR CP-MAS spectrum for resorcinol/3,5-difluorophenol $(90 \% / 10 \%)$ formaldehyde resin, 55197-105-B: a) ${ }^{1} \mathrm{H}$ and ${ }^{19} \mathrm{~F}$ decoupled spectrum, and b) ${ }^{1} \mathrm{H}$ and ${ }^{19} \mathrm{~F}$ dipolar-dephased spectrum 


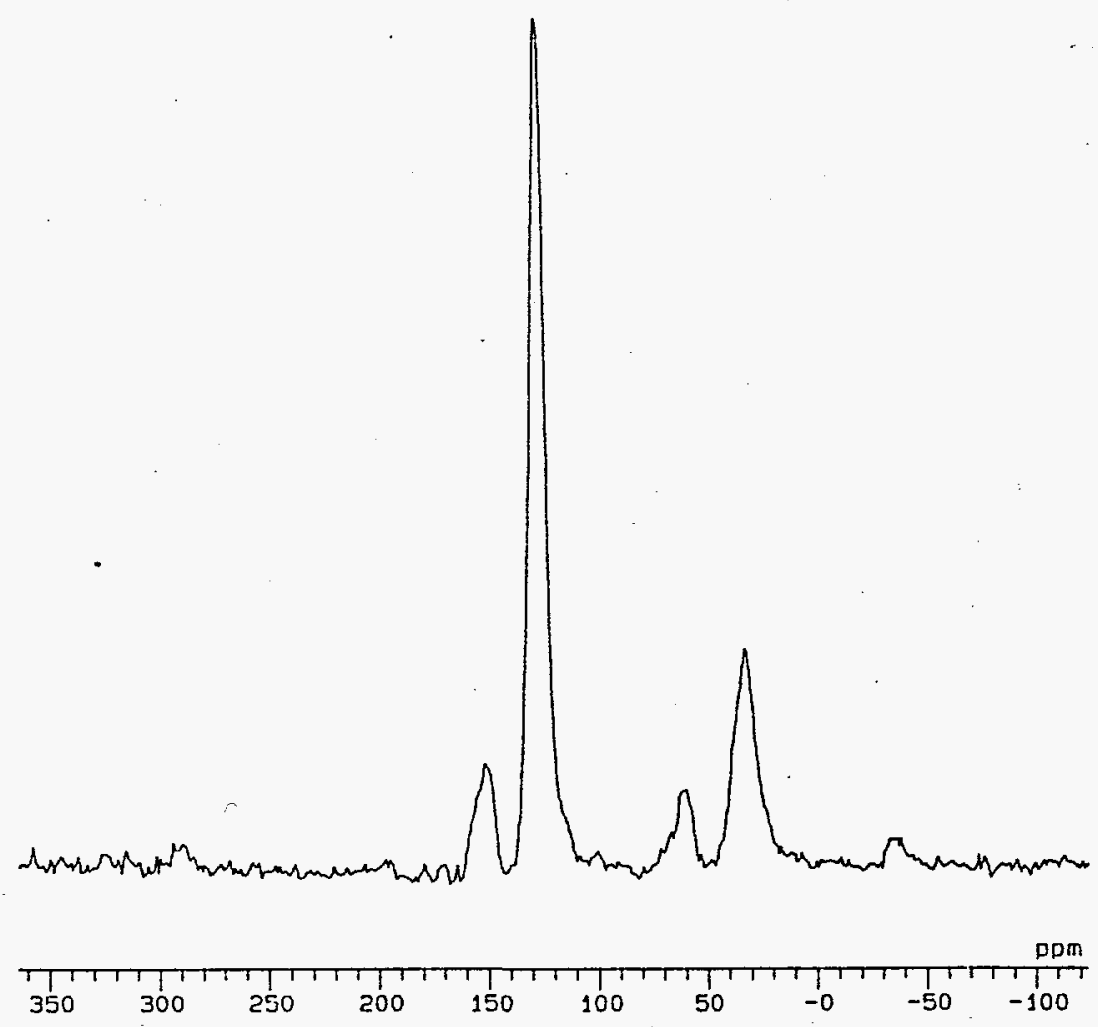

Figure 6. ${ }^{13} \mathrm{C}$ NMR CP-MAS spectrum for phenol formaldehyde (P-F) resin, 55197-68-A

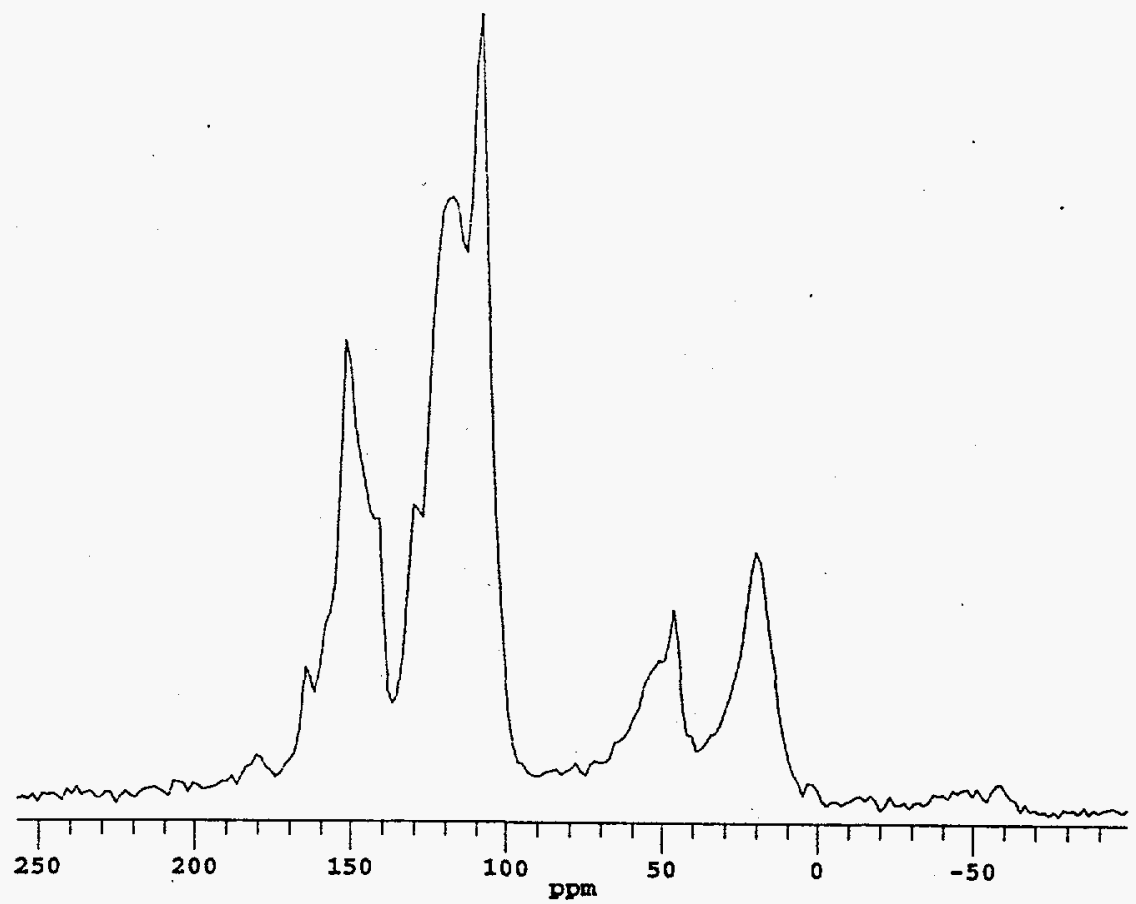

Figure 7. ${ }^{13} \mathrm{C}$ NMR CP-MAS spectrum for 3-fluorophenol formaldehyde resin, 55197-99-B 


\subsection{Solid-state ${ }^{19}$ F NMR Characterization of Fluorophenol Copolymer Resins}

Novel solid-state ${ }^{19} \mathrm{~F}$ NMR spectra of the fluorophenol copolymer resins were obtained and were used to define the status of the crosslinking occurring for these resins. In general, the ${ }^{1} \mathrm{H}$ decoupled fluorine signal was observed in two frequency domains, $-150 \mathrm{ppm}$ for "end-cap" fluorophenol groups and $-170 \mathrm{ppm}$ for "crosslinked" fluorophenol groups. The "end-cap" groups refer to fluorophenols that are tethered by a single methylene group to the resin matrix. If the fluorophenol moiety is an end-cap group, then it can freely undergo motion within the resin matrix, while crosslinked moieties (those with two or more crosslinks) are bound up tightly within the resin matrix. This physical distinction can be observed in the spectra by examining resonances with spinning sidebands. The spinning sidebands, which result from inhomogeneities in the magnetic field, are symmetrically disposed about the absorption band and their separation from the absorption peak is equal to the rate of sample spinning. The spinning sidebands can be reduced or made to disappear by adjusting the spinning rate of the sample within the NMR probe. This phenomenon has been observed for several of the fluorophenol resin copolymers prepared in this study, and combined with $\mathrm{K}_{d}$ data, the results correlate performance with the level of polymer crosslinking.

Figure 8 shows a solid-state ${ }^{19} \mathrm{~F}$ spectrum of resorcinol/2-fluorophenol formaldehyde resin $(95 \% / 5 \%)$. A smaller resonance is observed around $-150 \mathrm{ppm}$, while the main peak occurs at $-170 \mathrm{ppm}$, and this spectrum would be indicative of a reasonably well-crosslinked resin (the sample spinning speed was $10 \mathrm{kHz}$ ). The $\mathrm{K}_{\mathrm{d}}$ for this resin was about $4800 \mathrm{~mL} / \mathrm{g}$. On the other hand, Figure 9 shows the ${ }^{19} \mathrm{~F}$ NMR spectrum for resorcinol 4-fluorophenol formaldehyde resin $(90 \% / 10 \%)$, and indicates that there is little crosslinking of this fluorophenol within the resin matrix (i.e., it occurs primarily as an end-cap group). The $\mathrm{K}_{\mathrm{d}}$ for the 4-fluorophenol derivative was significantly less than standard R-F resin (about $3800 \mathrm{~mL} / \mathrm{g}$ ), and the drop in crosslinking occurring within the resin upon addition of $10 \%$ polymer modifier has a detrimental effect on the selectivity of the resin (and perhaps to a lesser extent, the capacity).

An experiment illustrating this characterization approach was conducted by spinning the sample at various rates. Figure 10 shows this experiment for the resorcinol/3,4-difluorophenol formaldehyde resin $(90 \% / 10 \%)$. In Figure 10a, the sample spinning rate was set at $2.0 \mathrm{kHz}$, and a single broad resonance appears around the $-150 \mathrm{ppm}$ frequency domain. When the sample spin rate was increased to $4.2 \mathrm{kHz}$, as shown in Figure $10 \mathrm{~b}$, the primary band became sharper, and additional spectral features appeared. A very broad, low-intensity resonance at 160-170 ppm appeared, as well as an even broader, less intense absorption around 200-210 ppm. The latter was a spinning sideband of the former, and its twin sideband was a shoulder on the large band at $-150 \mathrm{ppm}$. The increased sample spinning rate decreased the chemical shift anisotropy of the sample, thus sharpening the absorptions. The resonance at $160-170 \mathrm{ppm}$ was not observed at $2.0 \mathrm{kHz}$ because it was severely broadened into the baseline, but appeared sharper at $4.2 \mathrm{kHz}$. The primary band at $-150 \mathrm{ppm}$ did not show spinning sidebands at any of the three different spinning speeds because the motion of the end-cap groups within the resin matrix already had a frequency of motion faster than the sample spinning rate, and thus was not observed. A further increase in sample spinning rate to $10 \mathrm{kHz}$, as observed in Figure $10 \mathrm{c}$, showed further sharpening of both resonances at -150 and $-170 \mathrm{ppm}$ (i.e., reduction of chemical shift anisotropy). At this spinning rate, the spinning sidebands for the -170 resonance were no longer observed. This experiment suggested that the copolymer of this resin consisted primarily of 3,4-difluorophenol end-cap groups with only about $10-15 \%$ of the 3,4-difluorophenol copolymer in a crosslinked configuration. The effect on the performance of this resin by the reduced crosslinking was detrimental, and the $\mathrm{K}_{\mathrm{d}}$ for this resin was about $3400 \mathrm{~mL} / \mathrm{g}$. 


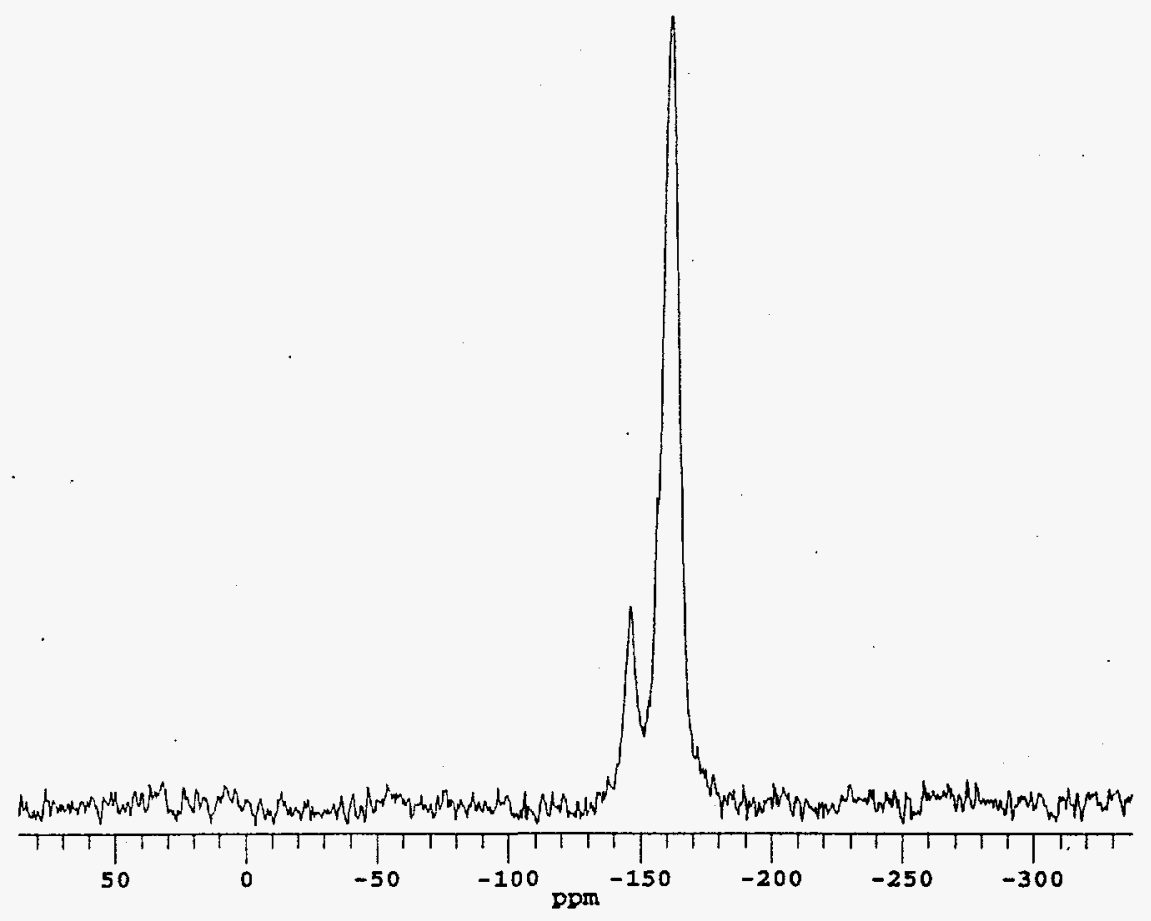

Figure 8. Solid-state ${ }^{19}$ F NMR spectrum for resorcinol/2-fluorophenol $(95 \% / 5 \%)$ formaldehyde resin, $55197-95-\mathrm{A}$ (sample spinning speed is $10 \mathrm{kHz}$ )

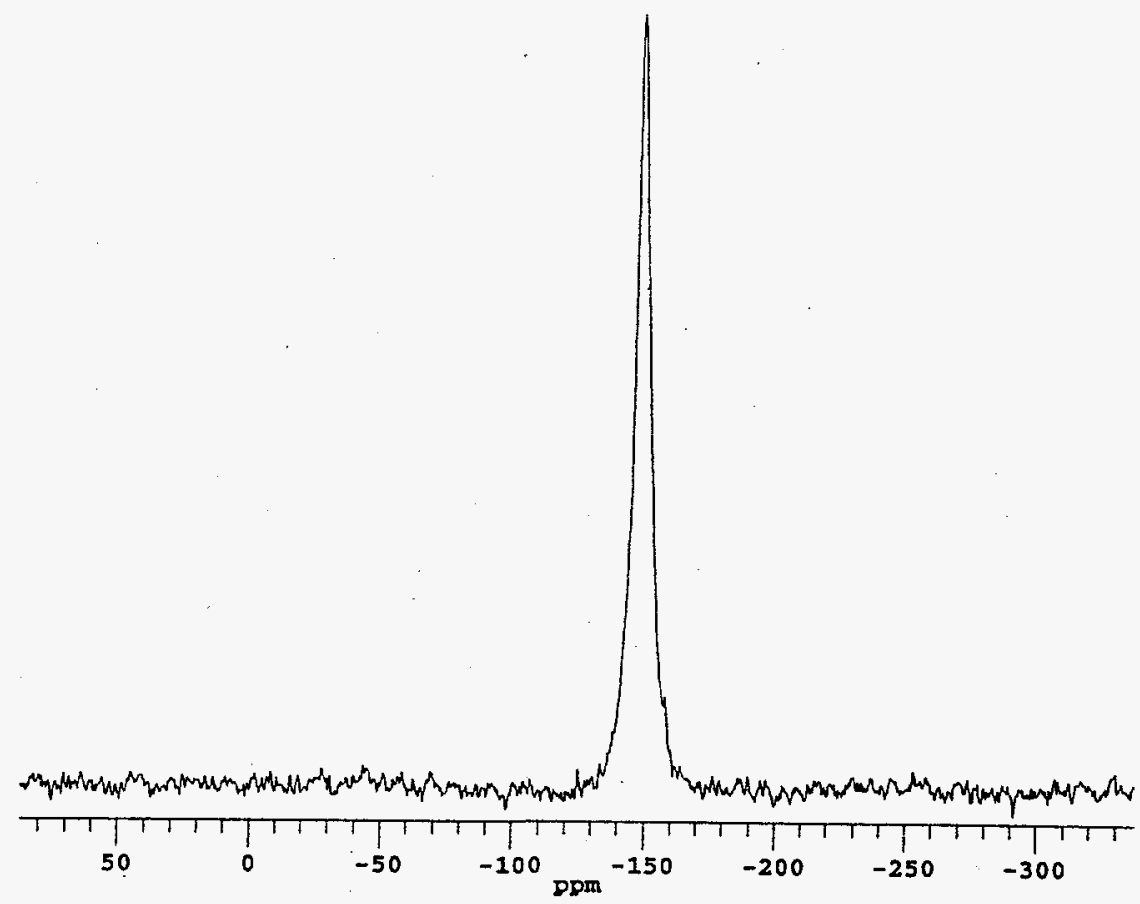

Figure 9. Solid-state ${ }^{19} \mathrm{~F}$ NMR spectrum for resorcinol/4-fiuorophenol $(90 \% / 10 \%)$ formaldehyde resin, $55197-100-\mathrm{B}$ (sample spinning speed is $10 \mathrm{kHz}$ ) 
ZHY 0 I(० pue 'zHY Z゙† (

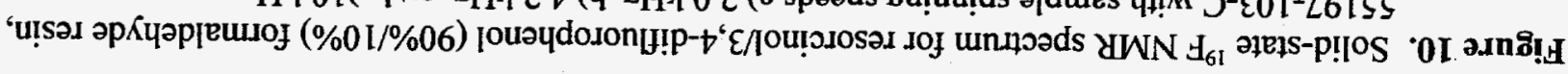

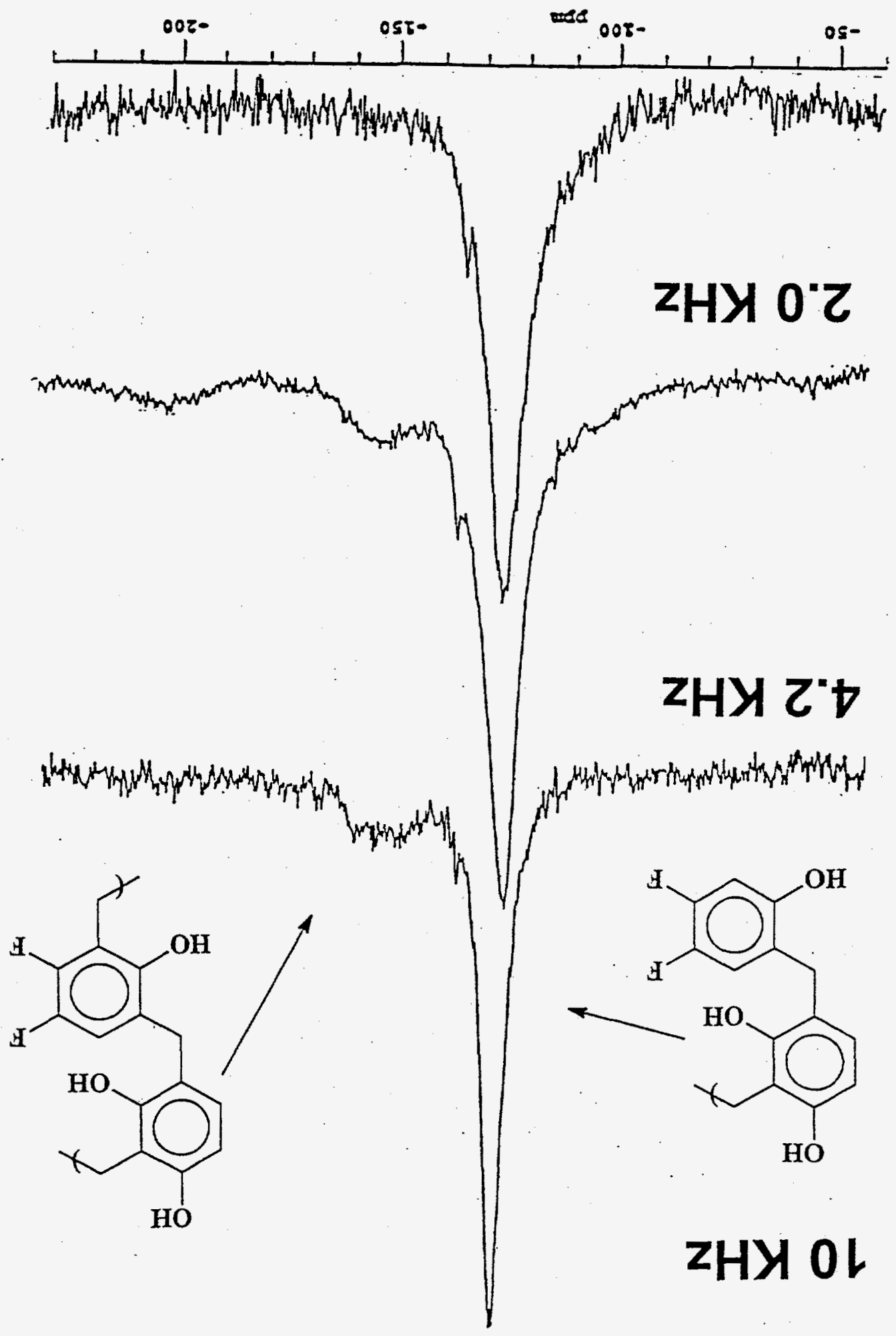


Similar results for the crosslinking studies as viewed from the ${ }^{19} \mathrm{~F}$ NMR perspective were observed for the phenol analogs. In relation to resin performance, it is difficult to sort out the degree of importance that the various factors have on capacity and selectivity. For example, the reduction of crosslinking for the monofluorophenols, and thus the effect on resin selectivity for cesium, is probably more important than reduction of capacity due to reduced basicity of the ion-exchange group (electronic effects imparted by the fluorine atom). For the difluorophenols, the electronic effects probably have an increased detrimental effect on the capacity of the resins, in addition to the reduction of selectivity arising from severely disturbed crosslinking. Hence, the difluorophenol copolymers generally have lowered performance (lower $\mathrm{K}_{d} s$ ) compared to their monofluorophenol analogs.

\subsection{Elemental Analyses of the Resin Copolymers}

Elemental analyses are presented in Table 2. The theoretical amounts are based upon putative structures for the ratios of the polymer components. The weight percent water for the resins was determined during batch $\mathrm{K}_{\mathrm{d}}$ analysis. Examination of these results also gives some additional clues about the amount of crosslinking in the resins. For sample 55197-100-B, the carbon is low and this situation would arise if there was reduced crosslinking between the ring groups. For the P-F resin, 55197-68-A, 56.45\% carbon was found compared to a calculated value of $57.02 \%$, which is another piece of supporting evidence for the etherified structural component of this resin.

\subsection{Resin Oxidation Studies}

Some of the fluorophenol copolymer resins were compared to R-F resin for their relative oxygen uptake characteristics. These experiments may be indicative about how easily the resins will oxidize, although the results must be carefully interpreted. For example, the experiments were run using pure oxygen, and thus the oxidizing environment is actually more harsh than realistic conditions (but does represent a worst case scenario). A comparison of oxygen uptake is shown in Figure 11. The resorcinol derivatives take up the largest amount of oxygen, and the greater the amount of fluorine in the polymer, the more oxygen that is absorbed or reacted with the resin. The kinetic studies show that R-F has a moderate rate of oxygen uptake, while the phenol derivatives are low in comparison and nearly level off after $1 \mathrm{~h}$ of exposure.

The fluorophenols themselves probably don't cause excess oxygen solubility because this arises from a cavity effect seen in perfluorocarbons rather than any special attractive interactions between the fluorocarbon and oxygen [7]. A few of these materials had their batch $\mathrm{K}_{d} \mathrm{~s}$ determined. The results were the following: phenol/3-fluorophenol $(90 \% / 10 \%), 45 \mathrm{~mL} / \mathrm{g}$; phenol/3,5-difluorophenol $(90 \% / 10 \%), 36 \mathrm{~mL} / \mathrm{g}$; and resorcinol/3-fluorophenol, $2273 \mathrm{~mL} / \mathrm{g}$ ). Hence the $\mathrm{K}_{\mathrm{d}} \mathrm{s}$ were reduced by anywhere from $50-75 \%$ of their original value by reaction with the oxygen. NMR studies also confirmed the oxidation of these materials; the solid-state ${ }^{13} \mathrm{C}$ CP-MAS NMR of oxidized resorcinol/3-fluorophenol $(90 \% / 10 \%)$ copolymer resin is shown in Figure 12. Here, ketone and quinone functionality are observed with resonances at 180-200 ppm, and ether functionality at $60 \mathrm{ppm}$, which are the typical indicators of resin oxidation [1]. 
Table 2. Elemental Analyses for R-F and P-F Copolymer Ion-Exchange Resins

Sample

PNL 55197-68-B

PNL 55197-71-A

PNL 55197-72-C

PNL 55197-94-A

PNL 55197-95-A

PNL 55197-96-B

PNL 55197-99-A

PNL 55197-100-B

PNL 55197-100-C

PNL 55197-102-A

PNL 55197-102-B

PNL 55197-103-C

PNL 55197-104-A

PNL 55197-105-B

PNL 55197-105-C

PNL 55197-68-A

PNL 55197-69-C

PNL 55197-71-D

PNL 55197-95-C

PNL 55197-96-A

PNL 55197-99-C

PNL 55197-100-A

PNL 55197-101-B

PNL 55197-101-C

PNL 55197-102-C

PNL 55197-103-A

PNL 55197-104-B

PNL 55197-104-C

PNL 55197-106-A

PNL 55197-106-B

PNL 55197-108-B

PNL 55197-108-C

PNL 55197-109-C

PNL 55197-95-B

PNL 55197-99-B

PNL 55197-108-A

$\%$ C Found

\%C Theory

$\begin{array}{rrrrr}45.96 & 47.36 & 4.12 & 4.05 & 11.87 \\ 44.50 & 45.68 & 3.63 & 3.89 & 14.09 \\ 46.04 & 45.26 & 3.79 & 3.98 & 12.30 \\ 46.51 & 46.99 & 3.47 & 3.86 & 12.92 \\ 43.98 & 47.12 & 3.59 & 3.91 & 13.50 \\ 46.98 & 46.99 & 3.89 & 3.86 & 10.13 \\ 47.20 & 47.12 & 3.89 & 3.91 & 8.80 \\ 45.82 & 46.99 & 3.99 & 3.86 & 10.74 \\ 46.72 & 47.12 & 3.98 & 3.91 & 7.84 \\ 46.87 & 46.66 & 3.78 & 3.80 & 10.97 \\ 48.12 & 46.99 & 4.03 & 3.88 & 7.90 \\ 47.85 & 46.66 & 3.84 & 3.80 & 6.58 \\ 47.33 & 46.99 & 4.14 & 3.88 & 8.79 \\ 47.13 & 46.66 & 3.70 & 3.80 & 5.86 \\ 46.97 & 46.99 & 4.04 & 3.88 & 8.32 \\ 56.45 & 57.02 & 5.02 & 4.10 & 12.93 \\ 46.75 & 46.86 & 3.74 & 4.60 & 12.81 \\ 48.04 & 48.74 & 3.83 & 4.29 & 9.81 \\ 47.67 & 51.26 & 3.90 & 4.24 & 8.41 \\ 49.08 & 51.60 & 3.89 & 4.30 & 7.15 \\ 49.80 & 51.26 & 4.05 & 4.24 & 8.63 \\ 49.01 & 51.60 & 4.11 & 4.30 & 8.63 \\ 52.03 & 51.26 & 4.30 & 4.24 & 9.10 \\ 49.51 & 51.60 & 4.25 & 4.30 & 8.10 \\ 49.60 & 50.44 & 4.12 & 4.14 & 6.97 \\ 50.79 & 51.13 & 4.35 & 4.24 & 7.50 \\ 49.14 & 50.44 & 4.20 & 4.14 & 8.47 \\ 49.29 & 51.13 & 4.33 & 4.24 & 7.18 \\ 49.32 & 50.44 & 4.14 & 4.14 & 7.78 \\ 49.76 & 51.13 & 4.26 & 4.21 & 5.86 \\ 50.85 & 51.80 & 4.15 & 4.37 & 5.41 \\ 51.86 & 51.79 & 4.31 & 4.36 & 5.00 \\ 47.34 & 51.80 & 4.42 & 4.35 & -19 \\ 44.50 & 44.81 & 3.39 & 3.47 & 9.04 \\ 44.27 & 44.81 & 3.44 & 3.47 & 9.22 \\ 41.75 & 42.42 & 2.98 & 2.54 & 9.20\end{array}$




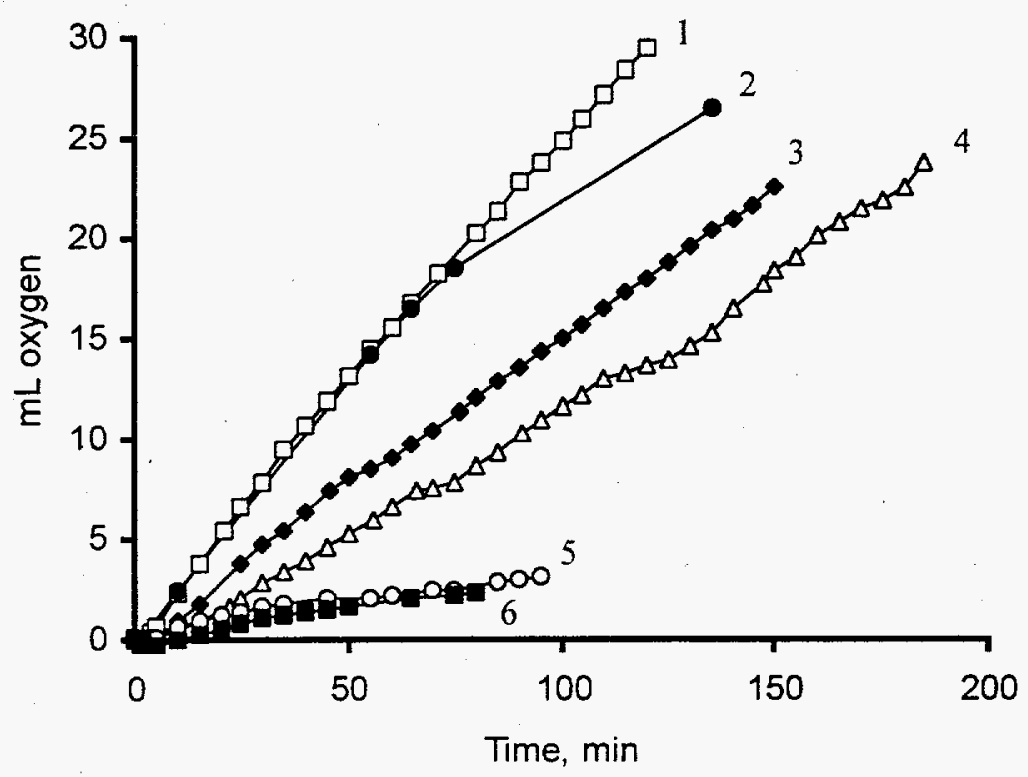

Figure 11. Oxygen uptake by selected resorcinol and phenol fluorophenol formaldehyde copolymers:

1) resorcinol/3,5-difluorophenol $(90 \% / 10 \%)$; 2) resorcinol/3-fluorophenol $(90 \% / 10 \%)$;

3) resorcinol/3,5-difluorophenol (95\%/5\%); 4) resorcinol, 100\%; 5) phenol/3,5-difluorophenol $(90 \% / 10 \%) ; 6)$ phenol/3-fluorophenol $(90 \% / 10 \%)$

\subsection{Resin Templating Studies}

The effect of using different alkali metal ions to "template" the resin during synthesis such that the ionexchange site is of optimal size for the cesium ion was of interest, as current synthetic procedures have called for the use of potassium ion to achieve this goal [2]. The approach used for the templating study was to synthesize R-F resin using the full range of alkali metal hydroxides. The resulting resins were then analyzed by solid-state NMR and batch $\mathrm{K}_{\mathrm{d}}$ analysis. Two different stoichiometries were used for the resin preparations (1 MOH: 1 resorcinol and $2 \mathrm{MOH}: 1$ resorcinol) to assess the templating effect that occurs when one or both of the resorcinol ring hydroxyl groups are deprotonated during synthesis.

The $\mathrm{K}_{\mathrm{d}} \mathrm{s}$ for the R-F resins prepared using different alkali metal ions are given in Tables 3 and 4 . The resins listed in Table 3 are the "as prepared" alkali metal forms of the resin, while Table 4 lists the same resins converted to the acid form before batch $\mathrm{K}_{\mathrm{d}}$ testing. As expected, the ionic forms contain more water than the acid forms, and there is a steady decrease in the amount of water that the resins will absorb progressing from lithium to cesium. Overall, the resins prepared in a 1:2 stoichiometry of $\mathrm{MOH}$ :resorcinol absorbed the most water. 


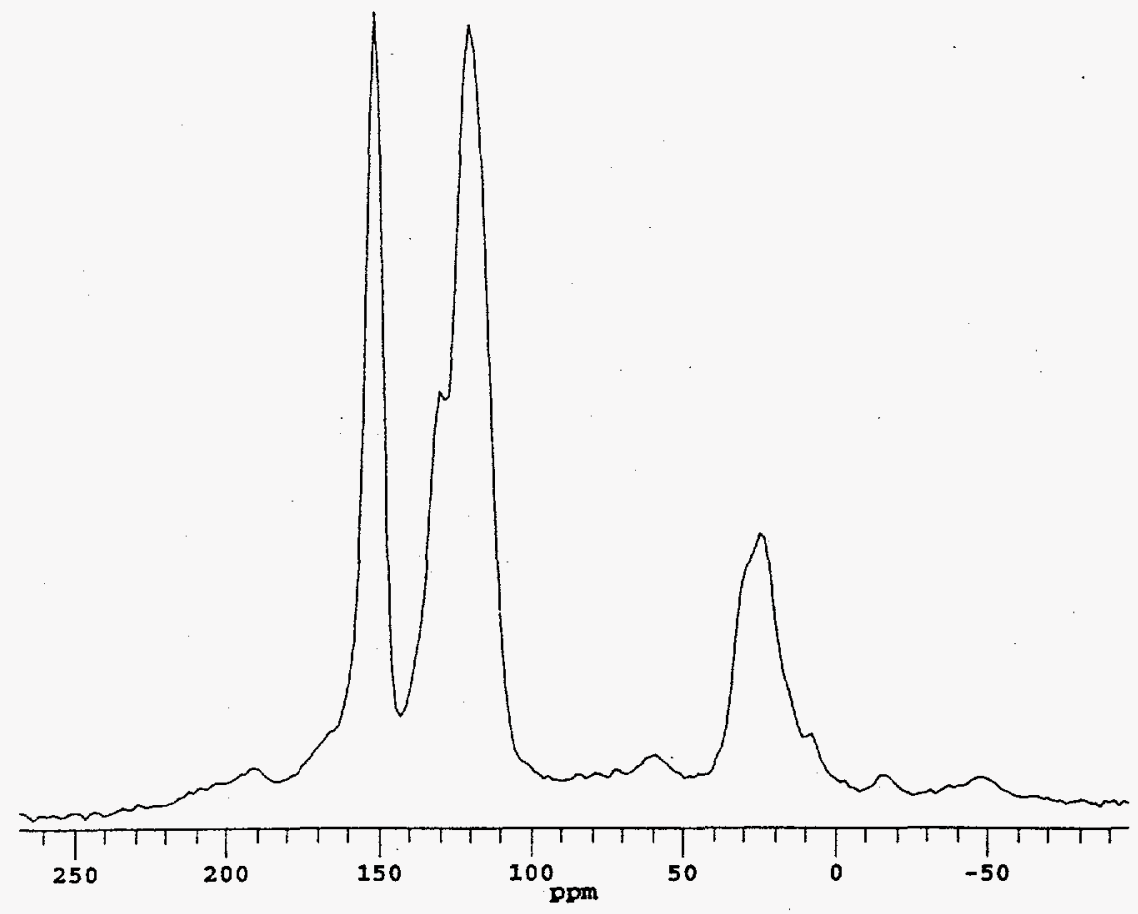

Figure 12. ${ }^{13} \mathrm{C}$ CP-MAS NMR of oxidized resorcinol/3-fluorophenol $(90 \% / 10 \%)$ copolymer resin (exposure time to oxygen was $2 \mathrm{~h}$ )

The $K_{d} s$ for the ionic forms, which are given in Table 3, also show a steady decrease in the $K_{d}$ value progressing from the sodium ion to the cesium ion, for both stoichiometries. This trend is expected based on the likely mechanism of selectivity as shown in Figure 13, which is directly related to the swelling of the resin. Swelling equilibrium is achieved by exchange of an alkali metal ion in the resin that has a larger hydrated ionic radius (e.g., sodium) with one possessing a smaller hydrated ionic radius from the external solution (e.g., cesium) [8]. When exchange occurs, the resin is able to contract (energy minimization), in this case due to the smaller effective volume of the hydrated cesium ion. The effect is most pronounced for resins where there is high strain or crosslinking. Hence resins prepared with cesium hydroxide or rubidium hydroxide have very small $\mathrm{K}_{d} \mathrm{~s}$ for their alkali metal forms because the energy resulting from polymer strain is already minimized. The lithium ion apparently has some other characteristics that cause it to fall short of the general trend observed for the other alkali metals.

The acid forms for all the resins have a fairly constant water content, and the resins prepared in the 2:1 stoichiometry (MOH:resorcinol) show reduced $\mathrm{K}_{d}$ values compared to the 1:1 stoichiometries. This may be due to resin oxidation enhanced by the fact that the resins with higher ionic content have higher polymer strain and are more susceptible to air oxidation. Overall, there is a leveling effect in the $\mathrm{K}_{d} \mathrm{~s}$ and any template effect would appear to be minimal. The resins prepared with the cesium template ion have the lowest $K_{d}$ in all cases, while those prepared with sodium ion have the highest $\mathrm{K}_{\mathrm{d}}$ in all but one case. 
Table 3. Distribution Coefficients for Ion-Templating Studies of R-F Resin in the Corresponding Ionic Form

\begin{tabular}{cccc} 
Template Ion & $\begin{array}{c}\text { Stoichiometry } \\
\text { (MOH:resorcinol) }\end{array}$ & $\begin{array}{c}\mathbf{K}_{\mathbf{d}} \\
(\mathbf{m L} / \mathbf{g})\end{array}$ & $\begin{array}{c}\text { Wt. \% } \\
\text { water }\end{array}$ \\
\hline $\mathrm{Li}$ & $1: 1$ & 4572 & 17.2 \\
$\mathrm{Na}$ & $1: 1$ & 5455 & 12.5 \\
$\mathrm{~K}$ & $1: 1$ & 4120 & 9.0 \\
$\mathrm{Rb}$ & $1: 1$ & 722 & 8.2 \\
$\mathrm{Cs}$ & $1: 1$ & 32 & 6.6 \\
$\mathrm{Li}$ & $2: 1$ & 2388 & 16.6 \\
$\mathrm{Na}$ & $2: 1$ & 3471 & 12.6 \\
$\mathrm{~K}$ & $2: 1$ & 2626 & 13.3 \\
$\mathrm{Rb}$ & $2: 1$ & 653 & 7.7 \\
$\mathrm{Cs}$ & $2: 1$ & 17 & 8.3
\end{tabular}

Table 4. Distribution Coefficients for Ion-Templating Studies of R-F Resin in the Acid Form

\begin{tabular}{cccc} 
Template Ion & $\begin{array}{c}\text { Stoichiometry } \\
\text { (MOH:resorcinol) }\end{array}$ & $\begin{array}{c}\mathbf{K}_{\mathbf{d}} \\
(\mathbf{m L} / \mathbf{g})\end{array}$ & $\begin{array}{c}\text { Wt. \% } \\
\text { water }\end{array}$ \\
\hline $\mathrm{Li}$ & $1: 1$ & 2725 & 4.9 \\
$\mathrm{Na}$ & $1: 1$ & 4093 & 6.4 \\
$\mathrm{~K}$ & $1: 1$ & 2614 & 6.6 \\
$\mathrm{Rb}$ & $1: 1$ & 3417 & 5.8 \\
$\mathrm{Cs}$ & $1: 1$ & 1129 & 5.3 \\
$\mathrm{Li}$ & $2: 1$ & 1403 & 4.2 \\
$\mathrm{Na}$ & $2: 1$ & 2076 & 6.0 \\
$\mathrm{~K}$ & $2: 1$ & 3588 & 6.2 \\
$\mathrm{Rb}$ & $2: 1$ & 2183 & 5.6 \\
$\mathrm{Cs}$ & $2: 1$ & 1454 & 6.6
\end{tabular}


A

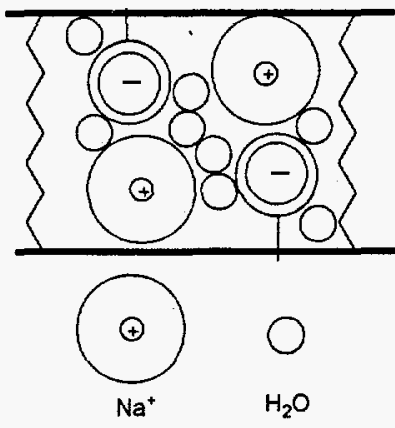

B

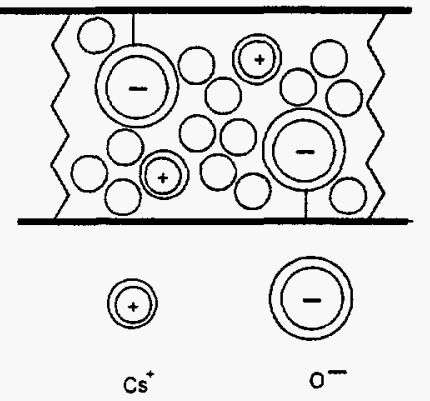

Figure 13. The relationship between swelling/contraction and selectivity for phenolic condensation polymers: A) before ion-exchange, resin is swollen; B) after ion-exchange, the smaller effective ionic radius of the cesium ion allows the polymer to contract (energy minimization)

The solid-state ${ }^{13} \mathrm{C}$ CP-MAS NMR spectra for the R-F resins had the typical spectral features. For the acid forms, the resolution of the resorcinol ring carbon resonances around $120 \mathrm{ppm}$ was greater, as has previously been observed for acid forms of the resin [1]. There were very slight differences in the amount of oxidation that could be discerned by NMR characterization of the different stoichiometric preparations; for the lithium templated resins, there was clearly more oxidation, and these resins also had smaller $\mathrm{K}_{d} s$. The particular reason for the greater oxidation of the lithium templated resins is not yet known; however, the greater polymer strain that the highly hydrated lithium ion may impart to the resin may be part of the reason for the lowered performance.

The results of elemental analyses for the R-F ion-templating studies are given in Table 5. The alkali metal "as prepared" forms are analyzed for carbon, hydrogen, and alkali metal for both 1:1 and 1:2 preparation stoichiometries (MOH:resorcinol). Additionally, the acid form resins were each analyzed for sodium ion and nitrogen since these resins were exposed to both sodium hydroxide and nitric acid during conversion to the acid form.

For the alkali metal forms, the carbon and metal analyses are generally low, while hydrogen is high, suggesting that there is more water and oxygen in the resins than accounted for by the theoretical model. In the case of the cesium materials, the carbon analyses are high, while the cesium levels match theory, and the high carbon may be present from the additional methylene crosslinking groups; this may indicate that some ion-templating is occurring, but is not conclusive. For the acid form of the resins, all the carbon analyses are low again. There is modest incorporation of nitrogen, probably in the form of nitro groups on the aromatic rings, which amounts to around $1 \%$ or less nitrogen and there is around $1 \%$ residual sodium from activation of these resins with sodium hydroxide during conversion to the acid form. The results from the acid forms indicate that there is more oxidation of the resin than seems to be accounted for, even in NMR spectra (which do show some oxidation). There is no clear indication that potassium or any of the alkali metals other than cesium may be templating ion-exchange sites in R-F resin. The template effect for cesium ion, if it is efficacious, would appear to be detrimental. Enhanced crosslinking may create a resin that is unable to swell without undergoing severe damage to the polymer structure. 
Table 5. Elemental Analyses for Alkali Metal-Templated R-F Resins

\begin{tabular}{|c|c|c|c|c|c|c|c|c|c|}
\hline $\begin{array}{c}\text { Resin } \\
\text { Template }\end{array}$ & $\begin{array}{l}\text { Stoichiometry } \\
\text { (MOH: } \\
\text { resorcinol) }\end{array}$ & $\begin{array}{l}\text { Resin } \\
\text { Form }\end{array}$ & $\begin{array}{l}\% \mathrm{C} \\
\text { Found }\end{array}$ & $\begin{array}{l}\% \mathrm{C} \\
\text { Theory }\end{array}$ & $\begin{array}{l}\% \mathrm{H}, \\
\text { Found }\end{array}$ & $\begin{array}{l}\text { \%H, } \\
\text { Theory }\end{array}$ & $\begin{array}{l}\% M, \\
\text { Found }\end{array}$ & $\begin{array}{l}\text { \%M, } \\
\text { Theory }\end{array}$ & $\begin{array}{l}\text { \%N, } \\
\text { Found }\end{array}$ \\
\hline $\mathrm{Li}$ & $1: 1$ & $\mathrm{Li}$ & 53.49 & 54.85 & 5.10 & 5.13 & 3.58, $\mathrm{Li}$ & $4.75, \mathrm{Li}$ & -- \\
\hline $\mathrm{Na}$ & 1:1 & $\mathrm{Na}$ & 47.88 & 51.29 & 4.76 & 4.43 & $13.17, \mathrm{Na}$ & $14.02, \mathrm{Na}$ & $\cdots$ \\
\hline $\mathrm{K}$ & $1: 1$ & K & 48.18 & 47.66 & 4.36 & 3.88 & $15.04, \mathrm{~K}$ & $22.15, \mathrm{~K}$ & --- \\
\hline $\mathrm{Rb}$ & $1: 1$ & $\mathrm{Rb}$ & 36.01 & 37.37 & 3.39 & 3.15 & 35.64 & 38.05 & $\cdots$ \\
\hline $\mathrm{Cs}$ & $1: 1$ & Cs & 32.14 & 30.91 & 2.90 & 2.59 & $48.38, \mathrm{Cs}$ & $48.84, \mathrm{Cs}$ & -- \\
\hline $\mathrm{Li}$ & $2: 1$ & $\mathrm{Li}$ & 46.30 & 50.63 & 4.77 & 4.59 & $5.98, \mathrm{Li}$ & $8.36, \mathrm{Li}$ & --- \\
\hline $\mathrm{Na}$ & $2: 1$ & $\mathrm{Na}$ & 39.18 & 42.70 & 4.16 & 3.80 & $18.55, \mathrm{Na}$ & $23.35, \mathrm{Na}$ & $\cdots$ \\
\hline $\mathrm{K}$ & $2: 1$ & $\mathrm{~K}$ & 32.69 & 36.27 & 2.97 & 3.34 & $23.60, \mathrm{~K}$ & $33.73, \mathrm{~K}$ & $\cdots$ \\
\hline $\mathrm{Rb}$ & $2: 1$ & $\mathrm{Rb}$ & 25.00 & 26.14 & 2.62 & 2.32 & $48.96, \mathrm{Rb}$ & $53.14, \mathrm{Rb}$ & $\cdots$ \\
\hline $\mathrm{Cs}$ & $2: 1$ & $\mathrm{Cs}$ & 21.58 & 19.95 & 2.17 & 1.90 & $62.87, \mathrm{Cs}$ & $63.00, \mathrm{Cs}$ & --- \\
\hline $\mathrm{Li}$ & $1: 1$ & $\mathrm{H}$ & 60.95 & 68.85 & 4.88 & 4.95 & $\begin{array}{l}<0.18, \mathrm{Li} \\
1.08 \% \mathrm{Na}\end{array}$ & 0 & 0.36 \\
\hline $\mathrm{Na}$ & $1: 1$ & $\mathrm{H}$ & 61.16 & 68.85 & 4.87 & 4.95 & $0.87, \mathrm{Na}$ & 0 & 0.45 \\
\hline $\mathrm{K}$ & $1: 1$ & $\mathrm{H}$ & 62.35 & 68.85 & 4.70 & 4.95 & $\begin{array}{l}<0.20, \mathrm{~K} \\
1.05 \% \mathrm{Na}\end{array}$ & 0 & 0.84 \\
\hline $\mathrm{Rb}$ & $1: 1$ & $\mathrm{H}$ & 63.80 & 68.85 & 5.05 & 4.95 & $\begin{array}{l}<0.16, \mathrm{Rb} \\
0.88 \% \mathrm{Na}\end{array}$ & 0 & 0.91 \\
\hline Cs & $1: 1$ & $\mathrm{H}$ & 62.79 & 68.85 & 5.05 & 4.95 & $\begin{array}{l}<0.17, \mathrm{Cs} \\
0.93 \% \mathrm{Na}\end{array}$ & 0 & 0.82 \\
\hline $\mathrm{Li}$ & 1:2 & $\mathbf{H}$ & 61.45 & 68.85 & 4.07 & 4.95 & $\begin{array}{l}<0.22, \mathrm{Li} \\
1.17 \% \mathrm{Na}\end{array}$ & 0 & 0.62 \\
\hline $\mathrm{Na}$ & $1: 2$ & $\mathbf{H}$ & 62.02 & 68.85 & 4.53 & 4.95 & $1.30, \mathrm{Na}$ & 0 & 0.38 \\
\hline $\mathrm{K}$ & $1: 2$ & $\mathbf{H}$ & 61.64 & 68.85 & 4.68 & 4.95 & $\begin{array}{l}<0.15, \mathrm{~K} \\
0.81 \% \mathrm{Na}\end{array}$ & 0 & 0.10 \\
\hline $\mathrm{Rb}$ & $1: 2$ & $\mathrm{H}$ & 62.28 & 68.85 & 4.86 & 4.95 & $\begin{array}{l}<0.12, \mathrm{Rb} \\
0.67 \% \mathrm{Na}\end{array}$ & 0 & 0.31 \\
\hline $\mathrm{Cs}$ & $1: 2$ & $\mathrm{H}$ & 60.58 & 68.85 & 4.90 & 4.95 & $\begin{array}{l}<0.15, \mathrm{Cs} \\
0.84 \% \mathrm{Na}\end{array}$ & 0 & 0.69 \\
\hline
\end{tabular}




\subsection{Conclusions/Recommendations}

This chapter summarizes the conclusions and observations presented in this report along with some recommendations. Previous research on R-F resin [1] taken in conjunction with the work presented in this report, has helped to define the relationship between structure and performance for both R-F and P-F resin.

The primary structural unit of R-F resin prepared using standard Bibler conditions is a 1,2,3,4-tetrasubstituted resorcinol ring bridged with methylene groups. About $80-85 \%$ of the polymer resin is composed of this unit. Likewise, P-F resin is composed primarily of 1,2,4-trisubstituted ring units (same as R-F, but with only one ion-exchange hydroxyl group). However, during preparation of P-F resin, using procedures similar to those for R-F resin, extensive etherification of the ring hydroxyl groups occurs, and the result is drastic loss of capacity for P-F resin as shown by the structures in Figure 14. The differing reactivities of the resorcinol ring versus the phenol ring account for the fact that R-F does not undergo the extensive etherification reaction that phenol does. Reaction of formaldehyde with resorcinol occurs primarily at the ring carbons in the 2-, 4-, or 6-position of the ring with very little reaction occurring at the hydroxyl group. Interestingly, P-F resin is apparently more chemically stable than R-F resin. The putative reason for the stability is that P-F resin is alkylated in the position para to the ring hydroxyl (methylene crosslink group), while R-F has reactively enhanced sites on the aromatic ring para to hydroxyl groups (since it is a 1,2,3,4-tetrasubstituted ring). This situation then allows facile oxidation of the R-F resin to occur, as in Figure 15 to give para-quinone structures, with concomitant loss of ion-exchange sites and performance of the resin. Attempts to enhance the chemical/oxidative stability of R-F resin by derivatization of sites para to the hydroxyl groups is currently being investigated [9].

The current work suggests that it is possible to prepare R-F and P-F resin copolymers and that NMR spectroscopy is a vital tool for correlation of structure with function for these complex systems. In general, copolymerization of R-F resin with hydroxybenzoic acids and fluorophenols gave a reduction of performance that may be primarily related to insufficient crosslinking of the resin. For P-F resin, fluorophenols reduce resin performance while hydroxybenzoic acids have a modest beneficial effect, which is most likely due to a modest increase in the capacity of the resin.

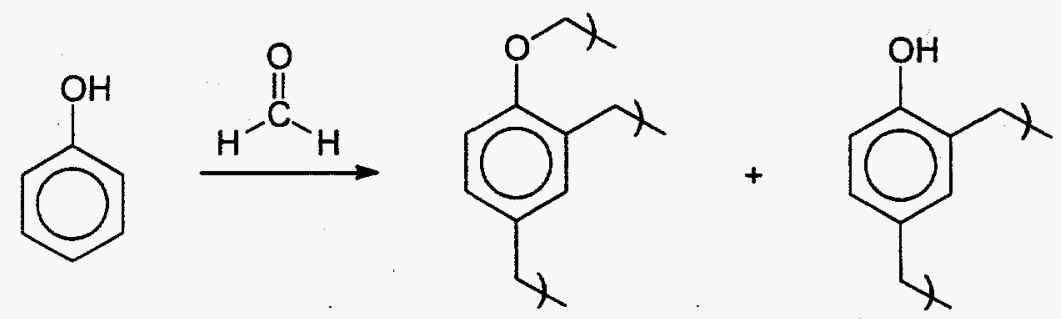

Figure 14. The two primary structural elements of $P-F$ resin 
<smiles>CCCCCC1=C(O)C(=O)C=C(CCC)C1=O</smiles>

Figure 15. Facile oxidation of R-F resin to give para-quinones

Ion-templating effects in R-F resin are probably minimal at best. Cesium ion apparently has a template effect, but one that is not desirable as evidenced by lower $\mathrm{K}_{d} s$. The reduced performance may be related to additional crosslinking of the polymer which is made possible by the smaller effective size of the hydrated cesium ion compared to sodium or potassium commonly used for synthesis of the resin. As the polymer is more highly crosslinked, it cannot swell as easily, and hence cannot undergo ion-exchange with cesium. The effect that is most important during synthesis is probably the stoichiometry of the alkali metal ion used. When all resorcinol ring hydroxyl groups are stoichiometrically deprotonated, the polymer probably cannot crosslink as efficiently, thus causing loss of selectivity for cesium ion and also rendering the polymer resin more susceptible to the effects of oxidation. 


\subsection{References}

[1] Hubler, T.L.; Franz, J.A.; Shaw, W.J.; Bryan, S.A.; Hallen, R.T.; Brown, G.N.; Bray, L.A.; Linehan, J.C., "Synthesis, Structural Characterization, and Performance Evaluation of Resorcinol-Formaldehyde (R-F) Ion-Exchange Resin," PNL-10744, Pacific Northwest National Laboratory, Richland, Washington, August 1995.

[2] "Cesium-Specific Phenolic Ion Exchange Resin," PCT Int. Appl WO 91,009,891 (11 July 1991; J.P. Bibler and R.M. Wallace to the U.S. Department of Energy); C.A., 115, 234200 (1991).

[3] Pennington, L.D.; Williams, M.B. Ind. Eng. Chem. 1959, 6, 759.

[4] Bray, L.A. PNL Test Procedure. "Determination of Batch Sorption Ratios for Ion-Exchange Materials Using Radionuclide Tracer Techniques," 1989, WTC-006-21-1.

[5] Gutsche, G. in "Calixarenes: A Versatile Class of Macrocyclic Compounds," Vicens, J.; Böhmer, V., eds. Kluwer Academic Publishers: Boston, Massachusetts, 1991, pp. 1-34.

[6] Brooks, K.P.; Kim, A.Y.; Kurath, D.E. "Assessment of Commercially Available Ion Exchange Materials for Cesium Removal from Highly Alkaline Wastes," TWRSPP-94-095, Pacific Northwest Laboratory, Richland, Washington, September 1994.

[7] a) Hulický, M.; Pavlath, A.E. "Chemistry of Organic Fluorine Compounds II: A Critical Review," American Chemical Society, ACS Monograph 187: Washington, D.C., 1995, p. 984. b) Afzal, J.; Ashlock, S.R.; Fung, B.M.; O'Rear, E.A. J. Am. Chem. Soc. 1986, 103, 3733. c) Hamza, M.H.A.; Serratrice, G.; Stébé, M.-J.; Delpuech, J.J. J. Am. Chem. Soc., 1981, 90, 3013. d) Maciejewski, A. J. Photchem. Photobio., A: Chemistry 1990, 51, 87.

[8] Helfferich, F. Ion Exchange; McGraw-Hill: New York, 1962, p. 121.

[9] Hubler, T.L.; Franz, J.A.; Shaw, W.J.; Hart, T.R.; Brown, G.N.; Linehan, J.C. "Chemical Derivatization to Enhance the Chemical/Oxidative Stability of Resorcinol-Formaldehyde (R-F) Resin." PNNL11327, Pacific Northwest National Laboratory, Richland, Washington, September 1996. 


\section{Distribution}

No. of

Copies

\section{OFFSITE}

2 DOE/Office of Scientific and Technical Information

J.P. Bibler

Westinghouse Savannah River Co.

Building 773-A

Aiken, SC 29802

J.M. Birmingham

Boulder Scientific Company

598 Third Street

Mead, CO 80542

Kurt Gerdes

DOE/Office of Technology

Development

Trevion II Building

12800 Middlebrook Road

Germantown, MD 20874

2 Oak Ridge National Laboratory

P.O. Box 2008, MS 6273

Oak Ridge, TN 37831-6223
C.P. McGinnis
R.D. Hunt

J.M. Shreeve

Department of Chemistry

University of Idaho

Moscow, ID 83844

J.L. Swanson

1318 Cottonwood Drive

Richland, WA 99352

M.C. Thompson

Savannah River Technology Center

P.O. Box 616

Aiken, SC 29802
No. of

Copies

ONSITE

3 DOE Richland Operations Office

$\begin{array}{ll}\text { J.A. Frey } & \text { K8-50 } \\ \text { J.P. Hanson } & \text { K8-50 } \\ \text { R.A. Pressentin } & \text { A6-54 }\end{array}$

12 Westinghouse Hanford Company

J.N. Appel

G3-21

S.A. Barker

R2-11

K.M. Eager

H5-27

R.R. Gadd

B4-49

K.A. Gasper

G3-21

R.A. Kirkbride

H5-27

M.J. Klem

H5-27

R.M. Orme

H5-27

D.L. Penwell

H5-27

I.E. Reep

G3-21

J.P. Sloughter

H5-27

D.J. Washenfelder

H5-27

41

Pacific Northwest National Laboratory

E.G. Baker

P8-38

W.F. Bonner

K9-14

K.P. Brooks

P7-43

G.N. Brown

P7-25

S.A. Bryan

P7-25

J.L. Buelt

P7-41

B.C. Bunker

K2-45

L.D. Carlson

P7-25

J.A. Franz

K2-38

R.T. Hallen

P8-38

T.R. Hart

K3-75

M.O. Hogan

P8-38

L.K. Holton

P7-43

T.L. Hubler (10)

P8-38

A.Y.Kim

K2-44

W.L.Kuhn

K2-21

Distr-1 
No. of

Copies

PNNL (contd)

D.E. Kurath $\quad$ P7-43

J.P. LaFemina K2-25

J.C. Linehan K2-38

N.J. Lombardo K9-91

S.J. Ortiz P8-38

R.K. Quinn K9-69

K.R. Savard K9-04

L.J. Sealock K2-10

S.C. Slate K9-14

T.L. Stewart $\quad$ K9-91

J.M. Tingey P7-25

Technical Report Files (5) 